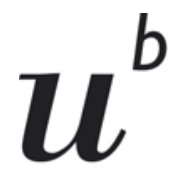

b

UNIVERSITÄT

BERN

Faculty of Business, Economics and Social Sciences

Department of Economics

\title{
Economic Openness and Fiscal Multipliers
}

Marco Riguzzi

14-06

September 2014

\section{DISCUSSION PAPERS}




\title{
Economic Openness and Fiscal Multipliers*
}

\author{
Marco Riguzzi ${ }^{\dagger}$
}

Working Paper Published:

September 2014

\begin{abstract}
This essay examines the implications of openness to trade, capital mobility, and exchange rate flexibility for the fiscal multiplier. It presents a New Open Economy Macroeconomics model which is extended with the formation of 'deep habits' by individual households. Hereby, an inter-temporal substitution effect is constituted, which causes monopolistically competitive producers to move their markups counter-cyclically and generates a positive fiscal multiplier of private consumption. The main outcome is a mechanism elaborating that both openness to trade and exchange rate flexibility limit the fiscal multiplier in equilibrium, and that capital mobility increases the fiscal multiplier in the short run. This dynamic model differs in its implications from a static model, such as the Mundell-Fleming model, and it is consistent with recent empirical findings.
\end{abstract}

JEL CLASSIFICATION: E12, E62, F4

KEY WORDS: Fiscal Multiplier, openness to trade, capital mobility, exchange rate flexibility

*The paper represents a condensed version of the first chapter of the PhD thesis "Three Essays in Applied Macroeconomics", Marco Claudio Riguzzi (2013), ISBN 978-3-86624-596-9, Winter Industries (Berlin). It was submitted to the International Economic Journal in August 2013.

${ }^{\dagger}$ Correspondence address: Marco Claudio Riguzzi, Winterthur Institute of Health Economics, ZHAW, Gertrudstrasse 15, P.O. Box, 8401 Winterthur, Switzerland. Telephone number: +41 58934 45 99. E-mail address: marco.riguzzi@zhaw.ch 


\section{Introduction}

Central contributions to macroeconomic research have been dedicated to the effect of fiscal stimulus on the business cycle, which is a topic of vital relevance not only in the face of the recent global crisis. Ramey (2011) provides a survey of empirical literature, summarizing that fiscal multipliers have been estimated to lie essentially between 0.8 and 1.5, depending on the setting and the method of estimation. ${ }^{1}$ While the responses of output and consumption to an increase in government spending have weakened over the past three decades, as it is reported by Canzoneri, Collard, Dellas, and Diba (2009), globalization at the same time has made economies increasingly interdependent. Two groups of authors stand out with their contributions to estimating empirically the effect of economic openness on the fiscal multiplier. Ilzetzki, Mendoza, and Vegh (2010) apply a structural VAR approach, providing evidence of both openness to trade and exchange rate flexibility being negatively related with fiscal effectiveness. Dellas, Neusser, and Wälti (2005) identify a positive effect of capital mobility on the fiscal multiplier. Both of these studies are based on a panel of OECD countries. Ilzetzki et al. (2010) consider developing countries in addition.

These empirical findings to some extent stand in contrast to static theory, in particular to the application of the IS-LM model to a two-country setting by Mundell and Fleming (1962), which implies that economic openness deteriorates the transmission mechanism of fiscal policy. While the well-known implications of the closed-economy version of the IS-LM model are that a fiscal expansion increases output, employment and consumption - with an output multiplier larger than one - while crowding out private investment, the open-economy version suggests that openness to trade, capital mobility, and exchange rate flexibility limit (or even entirely offset) the stimulating effect of fiscal policy: If borders are open for trade, an increase in income produced by a fiscal expansion drives up imports and therefore reduces the trade balance. This leads to an international spill-over effect. In a regime of flexible exchange rates, fiscal expansion raises the real interest rate and causes the currency to nominally appreciate. Under sluggish prices, this leads to an increase in the real exchange rate, and hence to a deterioration of the trade balance. In a small economy where capital is fully mobile, capital movement completely offsets the effect of the fiscal expansion on output. So far the implications of the static IS-LM theory.

More recently, Dellas et al. (2005) and Canzoneri et al. (2009) have introduced dynamic models describing the relationship of openness and fiscal effectiveness. In contrast to the IS-LM theory, Dellas et al. (2005) suggest that a flexible exchange rate regime does not limit the effectiveness of fiscal policy. In their model, the output multiplier can even be larger under flexible exchange rates than under a peg, as long as monetary policy does not follow a standard Taylor rule and counter the fiscal expansion.

The present essay aims to match the empirical evidence with a dynamic, stochastic model which explains for the effect of all the three main dimensions of economic openness in this respect (openness to trade, capital mobility, and exchange rate flexibility).

\footnotetext{
${ }^{1}$ To name a more extreme case, Auerbach and Gorodnichenko (2011) have applied regime switching structural VARs to this topic. They derive a point estimate of a fiscal multiplier going up to 2.48 if an economy is caught in a recession.
} 
The main predictions of the model are to be listed here:

- Openness to trade decreases the fiscal multiplier, which is in line with the empirical findings by Ilzetzki et al. (2010), and with the IS-LM model.

- Capital mobility increases the fiscal multiplier. This is consistent with the evidence provided by Dellas et al. (2005), but stands in contrast to the MundellFleming version of the IS-LM model.

- Exchange rate flexibility increases the fiscal multiplier during the short term of a business cycle. In the long run, there is a negative equilibrium effect. This is compatible with Dellas et al. (2005), as well as with Ilzetzki et al. (2010) who estimate a negative long-run effect.

The supply side of the model is based on a continuum of producers which operate under monopolistic competition and therefore attain a positive markup of price over cost. Price rigidity is introduced by means of convex price adjustment costs. Further, monetary policy is implemented via a standard Henderson-McKibbin-Taylor rule which targets inflation and the output gap, and, for the purpose of the research question, also the exchange rate. In order to model capital mobility, convex portfolio holding costs are added to the budget constraint of the households. Government consumption gives no utility to the households and is financed via a lump-sum tax.

A further important ingredient of the model is the formation of 'deep habits' by consumers at the level of individual goods, a property which is borrowed from the seminal paper by Ravn, Schmitt-Grohe, and Uribe (2005). The main implication is that households tend to consume more of a good today if they have already consumed it in the past. To motivate this empirically, one may think for example of brand loyalty which results from a process of personal identification of consumers with certain products. Another example are switching costs which may occur if a certain level of know-how is necessary in order to use a given product (think of computer platforms). A further reason for habit-driven behavior is personal taste, which may even intensify in goods which are consumed more frequently. Empirical evidence of habitual consumption behavior is provided by Chintagunta, Kyriazidou, and Perktold (2001). In the model, this kind of behavior of households provides firms with an incentive to move their markup in counter-cyclical fashion, creating a positive fiscal multiplier on private consumption, and hereby boosting up the multiplier on output. This stands in contrast to more classic New Keynesian (NK) models, in which a negative wealth effect of government spending typically crowds out consumption. The studies provided by Ravn, Schmitt-Grohe, and Uribe (2008) and Cantore, Levine, Melina, and Pearlman (2012) employ the mechanism of deep habits. However, they do not analyze economic openness as a determinant of the fiscal multiplier. Ravn et al. (2008) present a twocountry model with perfectly flexible prices and no internationally mobile bonds, while Cantore et al. (2012) model a closed economy. In the present essay, counter-cyclical firm markups are a key element for explaining the effect of openness to trade with regard to the fiscal multiplier.

The literature provides alternative ways of modeling a crowding-in effect of government spending on private consumption. Hall (2009) suggests that consumption and work effort are complementary in the utility function of households, and directly 
imposes a firm markup which is constructed to move counter-cyclically. Alternatively, rule-of-thumb consumers are discussed by Gali, Valles, and Lopez-Salido (2004, 2007). With this approach, it is assumed that consumers are not forward-looking and therefore fully spend their budget on consumption in every period, an assumption which is criticized by Colciago (2006) and Natvik (2010). Another approach, which however has gathered less attention, is provided by Kühn, Muysken, and Veen (2008) who assume that government spending directly enhances productivity of the firms in an economy. Finally, Canzoneri et al. (2009) present a different approach, assuming that households are not fully informed about the type of shock that hits an economy. That is, households cannot identify with certainty whether a shock has had an impact on government spending, technology, inflation or foreign preference for domestic goods. Since the latter three increase the permanent income of households, consumers react to any shock (the type of which being unknown to them) by increasing consumption.

The rest of this paper is organized as follows. Section 2 presents the derivation of the model. Section 3 shows the calibration, and section 4 presents the main results. Section 5 discusses the role of economic openness in the mechanism of a fiscal multiplier. Section 6 concludes.

\section{Model}

This section presents the main dynamic small open economy model. There is a continuum of monopolistically competitive producers incurring price adjustment costs. Monetary policy follows an interest rate rule which targets inflation, the output gap, and the exchange rate. Convex portfolio holding costs are part of the representative household's budget constraint in order to model capital mobility. Government consumption is financed via a lump-sum tax and provides no utility to the household. The domestic and foreign consumers, as well as the government, form deep habits of consumption at the level of individual goods, which creates an incentive for the monopolistically competitive producers to move their markup in a counter-cyclical way. As a result, the negative wealth effect induced by a fiscal expansion is compensated, which otherwise leads households to decrease consumption and increase work effort. In order to keep the model as simple as possible, it is assumed that foreign producers export their goods at an exogenous price, and that also consumption of domestic goods by foreign consumers follows an exogenous process. The foreign economy is not modeled in further detail.

\subsection{Domestic Households}

\subsubsection{Decision at time $t$}

The representative domestic household consumes a composite good of domestically produced individual goods, $c_{t}^{d}$, and a composite good of foreign individual goods, $c_{t}^{f}{ }^{2}$

\footnotetext{
${ }^{2}$ Throughout the text, the following conventions in terms of notation will be met: The subscript $t$ denotes the time period, the superscripts $d$ and $f$ denote that a variable belongs to the domestic or the foreign economy, respectively. The expression 'obj' is not an actual superscript but rather a part of the name of a variable such as $c^{\text {obj }}$. All variables are scalars, they are denoted in italics, and
} 
These two composite goods are combined to $c_{t}^{\text {obj }}$, the final index which is an argument of the utility function of the household:

$$
c_{t}^{\mathrm{obj}}=\left[\omega\left(c_{t}^{d}\right)^{1-1 / \xi}+(1-\omega)\left(c_{t}^{f}\right)^{1-1 / \xi}\right]^{1 /(1-1 / \xi)}
$$

This specification is borrowed from Ravn et al. (2008). It is an aggregator function with constant elasticity of substitution, as it is discussed by Dixit and Stiglitz (1977). Here, $\xi \in(1, \infty)$ denotes the elasticity of substitution between domestic and foreign goods, and $\omega \in(0,1)$ stands for the openness preference of the household. That is, $\omega$ by construction is unrelated to the actual substitutability of domestic and foreign goods with respect to observable features other than the country of origin. (Think of people wanting to buy a domestically produced good rather than a foreign one just because it comes from their own country, even if the goods themselves are identical. Then, such households are said to have a home bias, so $\omega>0.5$.) Hence, in the case where domestic and foreign goods are prefect substitutes $(\xi \rightarrow \infty$ and therefore $\left.c_{t}^{\text {obj }} \rightarrow \omega c_{t}^{d}+(1-\omega) c_{t}^{f}\right)$, it is only the home bias, $\omega$, and the prices which decide how the households split up their budget across domestic and foreign goods. ${ }^{3}$ On the other hand if $\xi \rightarrow 1$, meaning that domestic and foreign goods differ significantly (or are even complements), decreasing marginal utility attained both from consuming domestic goods and from consuming foreign goods implies that consumers care not only about their home bias, but that they also want to consume a mix of domestic and foreign goods, even if their home bias is strong.

The household chooses $c_{t}^{d}, c_{t}^{f}, h_{t}, B_{t}^{d}, B_{t}^{f}$ in order to maximize the present value of its present and future utility $U_{t}\left(c_{t}^{\text {obj }}, h_{t}\right) \forall t \in[0, \infty)$ subject to a budget constraint

$$
\begin{array}{ll}
\operatorname{max.} & \mathbb{E}_{t}\left\{\sum_{j=0}^{\infty} \beta^{j}\left[\frac{\left(c_{t+j}^{\mathrm{obj}}\right)^{1-\sigma}}{1-\sigma}-\psi \frac{h_{t+j}^{1+\phi}}{1+\phi}\right]\right\} \\
\text { s.t. } & P_{t}^{d} c_{t}^{d}+\varpi_{c, t}^{d}+e_{t} P_{t}^{f} c_{t}^{f}+\varpi_{c, t}^{f}+P_{t}\left(B_{t}^{d}+e_{t} B_{t}^{f}\right)= \\
& W_{t} h_{t}-T_{t}+P_{t-1}\left(R_{t-1} B_{t-1}^{d}+e_{t} R_{t-1}^{\star} B_{t-1}^{f}\right)-\frac{\chi}{2} P_{t}\left(e_{t} B_{t}^{f}\right)^{2}+\mathcal{F}_{t}:
\end{array}
$$

where $h_{t}$ denotes hours of labor, $B_{t}^{d}$ denotes domestic bond holdings, $B_{t}^{f}$ foreign bond holdings, $P_{t}^{d}$ the price of the domestic composite good, $P_{t}^{f}$ the price of the foreign composite good, $P_{t}$ the domestic consumer price index, $e_{t}$ the nominal exchange rate (in price notation), $W_{t}$ the nominal wage rate, $T_{t}$ a lump-sum tax, $R_{t}$ the domestic interest rate, $R^{\star}$ the foreign interest rate, and $\mathcal{F}_{t}$ the profits of domestic firms. ${ }^{4}$ All prices are denoted in domestic currency. As the budget constraint shows, it is costly for the household to hold foreign bonds, a circumstance which is modeled by a term that is convex-increasing in foreign bonds and weighted by $\chi>0$. Note that these

have a time period subscript. Constants/parameters are likewise denoted in italics but do not have a time subscript.

${ }^{3}$ In this extreme case where $\xi \rightarrow \infty$ : If $\omega /(1-\omega)>P_{t}^{d} e_{t}^{-1}\left(P_{t}^{f}\right)^{-1}$, the household buys domestic goods only.

${ }^{4}$ The superscript $\star$ denotes throughout the paper that a variable or parameter belongs to the foreign economy. $\mathbb{E}_{t}$ stands for the expected present value at time period $t$ of a function of future values. 
portfolio costs are a dead-weight loss to the economy; they are not redistributed, a feature which will show up in the general equilibrium condition of the model. The parameter $\chi$ serves as a measure of capital mobility (with a lower value of $\chi$ meaning that capital is more mobile). The parameter $\beta$ must lie strictly in between zero and one. This setup of budget constraint and portfolio holding cost is in the spirit of Dellas et al. (2005) and Collard, Dellas, and Diba (2011). The terms $\varpi_{c, t}^{d}$ and $\varpi_{c, t}^{f}$ emerge from the habit formation of past periods, as will be described in the following paragraph. It holds that $P_{t}^{d} c_{t}^{d}+\varpi_{c, t}^{d}=P_{t}^{d} x_{c, t}^{d}$ and $e_{t} P_{t}^{f} c_{t}^{f}+\varpi_{c, t}^{f}=e_{t} P_{c, t}^{f} x_{c, t}^{f}$. The first-order conditions of the representative household can be expressed as

$$
\begin{aligned}
\left(c_{t}^{\mathrm{obj}}\right)^{1 / \xi-\sigma} \omega\left(c_{t}^{d}\right)^{-1 / \xi} & =\lambda_{t} p_{t}^{d} \\
\left(c_{t}^{\mathrm{obj}}\right)^{1 / \xi-\sigma}(1-\omega)\left(c_{t}^{f}\right)^{-1 / \xi} & =\lambda_{t} r e r_{t} p_{t}^{f} \\
\psi h_{t}^{\phi} & =\lambda_{t} w_{t} \\
\lambda_{t} & =\beta R_{t} \mathbb{E}_{t}\left(\frac{\lambda_{t+1}}{\pi_{t+1}}\right) \\
\lambda_{t} & =\beta \frac{R_{t}^{\star}}{1+\chi b_{t}^{f}} \mathbb{E}_{t}\left(\frac{e_{t+1} \lambda_{t+1}}{e_{t} \pi_{t+1}}\right)
\end{aligned}
$$

where $\operatorname{rer}_{t}$ represents the real exchange rate. ${ }^{5}$

\subsubsection{Habit Formation}

The two composite goods $c_{t}^{d}$ and $c_{t}^{f}$, which go into the final index that delivers utility to the household, are habit-adjusted. Following the example of Ravn et al. (2005, 2008), 'deep habits' are formed at the level of each individual variety $i$ of domestic and foreign goods. Habit formation is external to the individual household, meaning that households are trying to 'catch up with the Joneses'. Technically, this is implemented simply by assuming that the habit stock of the domestic good of variety $i$, denoted by $s_{c, t}^{d}(i)$, creates a gap between $c_{t}^{d}(i)$ and $x_{t}^{d}(i)$. The latter denotes the actual (not habit-adjusted) amount of output of variety $i$ consumed by the household. Sticking to the case of domestic goods for the explanation of the mechanism, each variety $i$ belongs to the set $\{d\}$ of domestically produced goods. Let

$$
c_{t}^{d}=\left\{\int_{0}^{1}\left[x_{c, t}^{d}(i)-\theta s_{c, t}^{d}(i)\right]^{1-1 / \eta} \mathrm{d} i\right\}^{1 /(1-1 / \eta)}
$$

where $\theta \in[0,1)$ measures the intensity of habit formation, and $\eta>1$ denotes the elasticity of substitution across varieties. The mirror image is given with respect to foreign goods. From a technical point of view, the marginal utility derived by the households from one unit of variety $i$ is increasing in the habit stock built on variety $i$ in the past. From an economic point of view, this gives the household an incentive to consume more of variety $i$ today, if it has consumed $i$ yesterday. This yields a crucial incentive for the firms which are setting their markups, as will be discussed below. The habit stock evolves according to

$$
s_{c, t}^{d}(i)=\rho s_{c, t-1}^{d}(i)+(1-\rho) \bar{x}_{c, t}^{d}(i)
$$

\footnotetext{
${ }^{5}$ The following definitions are made: $\lambda_{t}=\Lambda_{t} P_{t}$, where $\Lambda_{t}$ is the Lagrange multiplier, $W_{t}=w_{t} P_{t}$, $p_{t}^{f}=P_{t}^{f}\left(P_{t}^{\star}\right)^{-1}, \operatorname{rer}_{t}=e_{t} P_{t}^{\star} P_{t}^{-1}, b_{t}^{f}=e_{t} B_{t}^{f}$, and $\pi_{t+1}=P_{t+1} P_{t}^{-1}$.
} 
where $\bar{x}_{c, t}^{d}(i)$ is the average amount of output of variety $i$ consumed per household. Hence, for a given level of $c_{t}^{d}$, the household chooses $x_{c, t}^{d}(i)$ to minimize its total expenditure on domestic goods, $\int_{0}^{1} P_{t}^{d}(i) x_{c, t}^{d}(i) \mathrm{d} i$, subject to equation (7). This yields the demand functions of the domestic household:

$$
\begin{aligned}
& x_{c, t}^{d}(i)=\left(\frac{P_{t}^{d}(i)}{P_{t}}\right)^{-\eta} c_{t}^{d}+\theta s_{c, t-1}^{d}(i) \\
& x_{c, t}^{f}(i)=\left(\frac{e_{t} P_{t}^{f}(i)}{P_{t}}\right)^{-\eta} c_{t}^{f}+\theta s_{c, t-1}^{f}(i)
\end{aligned}
$$

The last equation shows the demand of the domestic household for the foreign good of variety $i$, which is derived analogously to the domestic counterpart. Habits are formed for foreign goods in the same manner as for domestic goods. The expenditure of the household in period $t$ to cover its habits carried over from $t-1$ are given by $\varpi_{c, t}^{d}=\theta \int_{0}^{1} P_{t}^{d}(i) s_{c, t-1}^{d}$ and $\varpi_{c, t}^{f}=\theta \int_{0}^{1} e_{t} P_{t}^{f}(i) s_{c, t-1}^{f}$. The household takes this amount as given for its decision at time $t$.

\subsection{Domestic Government}

The domestic government forms deep habits of consumption at the level of each variety $i$, analogously to the household. Hence:

$$
g_{t}^{d}=\left\{\int_{0}^{1}\left[x_{g, t}^{d}(i)-\theta s_{g, t}^{d}(i)\right]^{1-1 / \eta} \mathrm{d} i\right\}^{1 /(1-1 / \eta)}
$$

In contrast to the household however, the government consumes domestically produced goods only. $g_{t}^{d}$ denotes the habit-adjusted composite good, while $x_{g, t}^{d}(i)$ represents the actual amount of variety $i$ that is consumed. The habit stock evolves according to

$$
s_{g, t}^{d}(i)=\rho s_{g, t-1}^{d}(i)+(1-\rho) x_{g, t}^{d}(i)
$$

The government does not buy any bonds and faces the static budget constraint

$$
P_{t} g_{t}=\int_{0}^{1} P_{t}^{d}(i) x_{g, t}^{d}(i) \mathrm{d} i
$$

where $g_{t}$ equals total real government expenditure and follows an exogenous process

$$
g_{t+1}=\gamma^{g} g_{t}+\left(1-\gamma^{g}\right) \bar{g}+\varepsilon_{t+1}^{g}
$$

Cost minimization yields a demand function which is analogous to the one of the representative household again:

$$
x_{g, t}^{d}(i)=\left(\frac{P_{t}^{d}(i)}{P_{t}}\right)^{-\eta} g_{t}^{d}+\theta s_{g, t-1}^{d}(i)
$$




\subsection{Domestic Firms}

Each firm $i$ is a monopolistic producer of a good of variety $i$, using linear technology with labor (hours worked) as the only input, so its individual output at time $t$ equals $h_{t}(i)$. It faces the total individual demand $y_{t}(i)=x_{c, t}^{d}(i)+x_{g, t}^{d}(i)+x_{c, t}^{d \star}(i)$, which is provided by domestic and foreign households, and the domestic government. Note at this point that due to portfolio holding costs of the household, and price adjustment costs of the firm, in a symmetric equilibrium the aggregate market clearing condition of the domestic economy must satisfy

$$
h_{t}=x_{c, t}^{d}+x_{g, t}^{d}+x_{c, t}^{d \star}+\frac{\chi}{2}\left(b_{t}^{f}\right)^{2}+\frac{\varphi_{p}}{2}\left(\pi^{d}-1\right)^{2} h_{t}
$$

Firm $i$ sets its price $P_{t}^{d}(i)$ which is denoted in domestic currency. It incurs a cost whenever it changes the price from one period to the next. This cost is given (in nominal terms) by

$$
\frac{\varphi_{p}}{2}\left(\frac{P_{t}^{d}(i)}{P_{t-1}^{d}(i)}-1\right)^{2} P_{t} h_{t}
$$

where $h_{t}$ denotes total aggregate supply in the symmetric equilibrium. Note that this price adjustment cost is not a tax, but a dead-weight loss to the economy. ${ }^{6}$ (Think of menu costs, contracts that are costly to be changed, etc.) Price rigidity is an important feature of this model. It makes monetary policy more effective. Exchange rate targeting is crucial for explaining the effect of openness on the fiscal multiplier. Also, price rigidity causes the firms to change their markup through a 'wage channel' rather than a 'price channel.' Firm $i$ maximizes the profit function

$$
\mathbb{E}_{0} \sum_{t=0}^{\infty} \Phi_{0, t}\{\left[P_{t}^{d}(i)-W_{t}\right] \cdot \underbrace{\left[x_{c, t}^{d}(i)+x_{g, t}^{d}(i)+x_{c, t}^{d \star}(i)\right]}_{=y_{t}(i)}-\frac{\varphi_{p}}{2}\left(\frac{P_{t}^{d}(i)}{P_{t-1}^{d}(i)}-1\right)^{2} P_{t} h_{t}\}
$$

As the firm makes its price-setting decision, it takes into account the demand functions and the laws of habit stock evolution of the domestic and foreign households and the government. This is crucial for the model's predictions concerning the effects of a fiscal expansion, as it yields that firms react to changes in aggregate demand by moving their markup in counter-cyclical fashion.

The mechanism of counter-cyclical markups, which is analogous to Ravn et al. (2008), is to be explained here. Each firm $i$ faces an individual demand function of the form

$$
x_{t}^{d}(i)=\left[P_{t}^{d}(i)\right]^{-\eta} h_{t}(i)+\theta s_{t-1}^{d}(i)
$$

This individual demand is the sum of a price-elastic component, $\left[P_{t}^{d}(i)\right]^{-\eta} h_{t}(i)$, and a price inelastic component, $\theta s_{t-1}^{d}(i)$. The elastic component is proportional to aggregate demand of the current period, $h_{t}$, while the inelastic component stems from the habit formation of past periods. Therefore, the price elasticity of the individual demand function that firm $i$ faces is a weighted average of $\eta$ and 0 . As a result of an increase in

\footnotetext{
${ }^{6}$ Price adjustment costs of this type are used for example by Dellas et al. (2005).
} 
current aggregate demand at time $t$ (caused by a fiscal expansion), the weight of the elastic component increases, making the individual demand function more price-elastic. In other words, the price elasticity of individual demand is pro-cyclical. This provides a clear intra-temporal incentive for the firm to charge a counter-cyclical markup.

In addition, there is an inter-temporal incentive: As firms anticipate that the habit stock is a weighted average of past sales, they face a dynamic profit maximization problem. By decreasing the markup today, a firm can acquire 'new customers' which will return tomorrow as they will be 'bound to their own habits'. As the results will show, this inter-temporal incentive is even more intense regarding that in the phase of transition after a fiscal shock, firms are even able to slightly increase their markup above the steady state level for a few periods, and hereby partly compensate for the initial drop in the markup.

Firm $i$ chooses the optimal levels of $P_{t}^{d}(i), x_{c, t}^{d}(i), x_{g, t}^{d}(i), x_{c, t}^{d \star}(i), s_{c, t}^{d}(i), s_{g, t}^{d}(i)$, and $s_{c, t}^{d \star}(i)$, taking as given $\Phi_{0, t}, W_{t}, P_{t}^{d}, P_{t}^{d \star}, c_{t}^{d}, g_{t}^{d}, c_{t}^{d \star}$, and the initial conditions $s_{c, t-1}^{d}(i)$, $s_{g, t-1}^{d}(i)$, and $s_{c, t-1}^{d \star}(i)$. The first-order conditions of the symmetric equilibrium are given by

$$
\begin{aligned}
0= & p_{t}^{d} y_{t}-\varphi_{p}\left(\pi_{t}^{d}-1\right) \pi_{t}^{d} h_{t}-\eta\left[\nu_{c, t}\left(x_{c, t}^{d}-\theta s_{c, t-1}^{d}\right)\right. \\
& \left.+\nu_{g, t}\left(x_{g, t}^{d}-\theta s_{g, t-1}^{d}\right)+\nu_{c, t}^{\star}\left(x_{c, t}^{d \star}-\theta s_{c, t-1}^{d \star}\right)\right] \\
& +\beta \varphi_{p} \frac{\lambda_{t+1}}{\lambda_{t}} \pi_{t+1}^{d}\left(\pi_{t+1}^{d}-1\right) h_{t+1} \\
w_{t}= & p_{t}^{d}-\nu_{c, t}-(1-\rho) \varrho_{c, t} \\
w_{t}= & p_{t}^{d}-\nu_{g, t}-(1-\rho) \varrho_{g, t} \\
w_{t}= & p_{t}^{d}-\nu_{c, t}^{\star}-(1-\rho) \varrho_{c, t}^{\star} \\
\varrho_{c, t}= & \beta \frac{\lambda_{t+1}}{\lambda_{t}}\left(\rho \varrho_{c, t+1}-\theta \nu_{c, t+1}\right) \\
\varrho_{g, t}= & \beta \frac{\lambda_{t+1}}{\lambda_{t}}\left(\rho \varrho_{g, t+1}-\theta \nu_{g, t+1}\right) \\
\varrho_{c, t}^{\star}= & \beta \frac{\lambda_{t+1}}{\lambda_{t}}\left(\rho \varrho_{c, t+1}^{\star}-\theta \nu_{c, t+1}^{\star}\right)
\end{aligned}
$$

where $\pi_{t}^{d}=P_{t}^{d}\left(P_{t-1}^{d}\right)^{-1}, \lambda_{t+1} \lambda_{t}^{-1}=\Lambda_{t+1} P_{t+1} \Lambda_{t}^{-1} P_{t}^{-1}$, and $W_{t}=w_{t} P_{t}$. Again, $\Lambda_{t}$ is the Lagrange multiplier of the representative household's optimization problem. It is related to the firm's discount factor by assuming that $\Phi_{0, t}=\beta^{j} \Lambda_{t} \Lambda_{0}^{-1}$. Further, $\nu_{c, t}$, $\nu_{g, t}, \nu_{c, t}^{\star}, \varrho_{c, t}, \varrho_{g, t}$, and $\varrho_{c, t}^{\star}$ are the Lagrange multipliers of firm $i$ 's optimization problem. Note that, since initial habit stocks are assumed to be identical across different varieties, all domestic firms will charge the same price in a symmetric equilibrium. Therefore, $P_{t}^{d}(i)=P_{t}^{d}$ for all $i$. It follows that in equilibrium, all prices and consumption quantities will be the same across varieties $i$. In other words, in the symmetric equilibrium, $i$ drops. For matters of illustration, let the real markup per unit of output that the producer gets in the symmetric equilibrium be denoted as $\mu_{t}=p_{t}^{d}-w_{t}$.

\subsection{Rest of the World}

For simplicity, since the model sketches a small open economy, the bond holdings of foreign households are not modeled explicitly. Also, only the consumption of domestic 
goods by foreign households is part of the model (but not their consumption of foreign goods), and foreign households pay no taxes as their government is not modeled. The consumption of domestic goods by foreign households follows the exogenous process

$$
c_{t+1}^{d \star}=\gamma^{d \star} c_{t}^{d \star}+\left(1-\gamma^{d \star}\right) \bar{c}^{d \star}+\varepsilon_{t+1}^{d \star}
$$

where $c_{t}^{d \star}$ is the habit-adjusted composite good

$$
c_{t}^{d \star}=\left\{\int_{0}^{1}\left[x_{c, t}^{d \star}(i)-\theta s_{c, t}^{d \star}(i)\right]^{1-1 / \eta} \mathrm{d} i\right\}^{1 /(1-1 / \eta)}
$$

Foreign households form habits over consumption of domestic goods at the level of each variety $i$, in the same manner as the domestic households do. The habit stock evolves according to

$$
s_{c, t}^{d \star}(i)=\rho s_{c, t-1}^{d \star}(i)+(1-\rho) x_{c, t}^{d \star}(i)
$$

The foreign household demands the amount $x_{c, t}^{d \star}(i)$ of variety $i$, minimizing its expenditure $\int_{0}^{1} x_{c, t}^{d \star}(i) P_{t}^{d \star}(i) e_{t}{ }^{-1} \mathrm{~d} i$. This yields the demand function for variety $i$ :

$$
x_{c, t}^{d \star}(i)=\left(\frac{P_{t}^{d}(i)}{e_{t} P_{t}^{\star}}\right)^{-\eta} c_{t}^{d \star}+\theta s_{c, t-1}^{d \star}(i)
$$

The foreign firm $(i)$ sells its goods at a price per unit of $P_{t}^{f}$, denoted in foreign currency, which is exogenously given by

$$
p_{t+1}^{f}=\gamma^{f} p_{t}^{f}+\left(1-\gamma^{f}\right) \bar{p}^{f}+\varepsilon_{t+1}^{f}
$$

\subsection{Symmetric General Equilibrium}

As mentioned above, due to symmetry and the assumption of an identical initial stock of habits across varieties, prices and output quantities are identical across all varieties $i$. Therefore, the $i$-suffix is neglected for the characterization of the symmetric general equilibrium.

\subsubsection{Price Level}

Private consumption is simply defined as $c_{t}=x_{c, t}^{d}+x_{c, t}^{f}$, while government consumption is equal to $g_{t}=x_{g, t}^{d}$. The consumer price index (CPI) is defined as an expenditure weighted average of the prices of the composite goods, which is similar to the model of Ravn et al. (2008):

$$
P_{t}=\gamma P_{t}^{d}+(1-\gamma) e_{t} P_{t}^{f} \quad \text { where } \quad \gamma=\frac{\bar{P}^{d}\left(\bar{x}_{c}^{d}+\bar{x}_{g}^{d}\right)}{\bar{P}^{d}\left(\bar{x}_{c}^{d}+\bar{x}_{g}^{d}\right)+e_{t} \bar{P}^{f} \bar{x}_{c}^{f}}
$$

By defining $p_{t}^{d}=P_{t}^{d} P_{t}^{-1}$ and $p_{t}^{f}=P_{t}^{f}\left(P_{t}^{\star}\right)^{-1}$, where $P_{t}^{\star}$ is the foreign CPI which is exogenous to the domestic small open economy, the definition of the domestic real exchange rate $\left(\operatorname{rer}_{t}=e_{t} P_{t}^{\star} P_{t}^{-1}\right)$ can be used to find: $\operatorname{rer}_{t} p_{t}^{f}=e_{t} P_{t}^{f} P_{t}^{-1}$. Hence, dividing the domestic CPI formula by $P_{t}$ itself yields

$$
1=\gamma p_{t}^{d}+(1-\gamma) \operatorname{rer}_{t} p_{t}^{f}
$$




\subsubsection{Aggregate Output and Market Clearing}

The trade balance is given by

$$
T B_{t}=x_{c, t}^{d \star}-x_{c, t}^{f}
$$

Adding up domestic aggregate consumption, government spending, and the trade balance yields aggregate output, $y_{t}=c_{t}+g_{t}+T B_{t}$, which is equal to

$$
y_{t}=x_{c, t}^{d}+x_{c, t}^{f}+x_{g, t}^{d}+\underbrace{x_{t}^{d \star}-x_{c, t}^{f}}_{=T B_{t}}=x_{c, t}^{d}+x_{g, t}^{d}+x_{t}^{d \star}
$$

As mentioned above, due to portfolio holding costs of the household, and price adjustment costs of the firm, in the symmetric equilibrium the aggregate market clearing condition is

$$
h_{t}=\underbrace{x_{c, t}^{d}+x_{g, t}^{d}+x_{c, t}^{d \star}}_{=y t}+\frac{\chi}{2}\left(b_{t}^{f}\right)^{2}+\frac{\varphi_{p}}{2}\left(\pi^{d}-1\right)^{2} h_{t}
$$

This specification takes into account the assumption that portfolio costs of the households, and price adjustment costs of the firms, are a dead-weight loss to the economy.

\subsubsection{Asset Market}

The net return which the domestic economy attains from foreign bond holdings must equal the trade balance $\left(T B_{t}\right)$, minus the dead-weight loss from portfolio holding and price adjustment $\left(D W L_{t}\right)$. It must hold that

$$
b_{t}^{f}=\frac{e_{t}}{e_{t-1} \pi_{t}} R_{t-1}^{\star} b_{t-1}^{f} \underbrace{-h_{t}+y_{t}}_{=-D W L_{t}} \underbrace{+x_{c, t}^{d \star}-x_{c, t}^{f}}_{=T B_{t}}
$$

where $b_{t}^{f}=e_{t} B_{t}^{f}$.

\subsubsection{Domestic Inflation}

The inflation rate of the domestic CPI, $\pi_{t}=P_{t} P_{t-1}^{-1}$, is related to the price of the domestic good as follows:

$$
\pi_{t}^{d}=\frac{P^{d}}{P_{t-1}^{d}}=\frac{p_{t}^{d} P_{t}}{p_{t-1}^{d} P_{t-1}}=\frac{p_{t}^{d}}{p_{t-1}^{d}} \pi_{t} \Rightarrow p_{t}^{d}=\frac{\pi_{t}^{d}}{\pi_{t}} p_{t-1}^{d}
$$

The inflation rate of the foreign CPI, $\pi^{\star}=P_{t}^{\star}\left(P_{t-1}^{\star}\right)^{-1}$, must only satisfy $\pi_{t}^{\star}=$ $p_{t}^{f}\left(p_{t-1}^{f}\right)^{-1}$. This is due to the fact that the foreign economy is large and therefore the foreign prices are not influenced by the domestic economy. However, the foreign CPI influences the domestic CPI. The two are linked by

$$
\operatorname{rer}_{t}=\frac{p_{t}^{f}}{p_{t-1}^{f}} \cdot \frac{1}{\pi_{t}} \operatorname{rer}_{t-1}
$$




\subsubsection{Foreign Interest Rate}

The utility function of the foreign consumer is $U_{t}^{\star}=\left(c_{t}^{d \star}\right)^{1-\sigma} /(1-\sigma)$. Therefore, the foreign interest rate must satisfy

$$
\left(c_{t}^{d \star}\right)^{-\sigma}=\beta R_{t}^{\star} \mathbb{E}_{t}\left[\frac{\left(c_{t+1}^{d \star}\right)^{-\sigma} p_{t}^{f}}{p_{t+1}^{f}}\right]
$$

\subsubsection{Monetary Policy}

The domestic central bank sets its interest rate following a Henderson-McKibbinTaylor type of a rule: ${ }^{7}$

$$
\begin{aligned}
\log \left(R_{t}\right)= & \rho_{r} \log \left(R_{t-1}\right)+\left(1-\rho_{r}\right)\left\{\log (\bar{R})+\gamma_{\pi}\left[\log \left(\pi_{t}\right)-\log (\bar{\pi})\right]\right. \\
& \left.+\gamma_{y}\left[\log \left(y_{t}\right)-\log (\bar{y})\right]+\gamma_{e}\left[\log \left(e_{t}\right)-\log (\bar{e})\right]\right\}
\end{aligned}
$$

\section{Calibration}

I have used parameter values which are common in the open economy literature. The benchmark calibration is reported in table 1 . Openness preference is set to 0.85 , the value used by Dellas et al. (2005), which represents a home bias of consumers as it lies above 0.5. For habit persistence, that is the rate at which habit stocks are carried over from one period to the next, Ravn et al. (2008) use a value of 0.9876. For the present model, a slightly more moderate value of 0.9 is assumed. The intensity of habit formation is calibrated in between the two alternative values suggested by Ravn et al. (2008), which are 0.52 and 0.57. The fiscal policy shock is the only stochastic shock to the model. Government expenditure is assumed to follow an AR(1) process with an autoregressive parameter of 0.55.

\section{Results}

The solution of the model is computed after taking a first-order linear approximation around the deterministic steady state. The main results are presented in tables 2 and 3. Each table reports fiscal multipliers on aggregate output and fiscal multipliers on private consumption in separate columns. These multipliers are computed for different monetary policy regimes:

(1) A full monetary policy setting with threefold targeting as described above. That is, inflation targeting, output gap targeting, and exchange rate targeting are effective.

(2) A more classic monetary policy setting with inflation targeting and output gap targeting only. Exchange rate targeting is disabled $\left(\gamma_{e}=0\right)$.

(3) A setting with flexible prices.

\footnotetext{
${ }^{7}$ The rule is based on Henderson McKibbin (1993) and Taylor (1993).
} 
Table 2 reports separately the multipliers attained under a home bias and the multipliers attained under a high degree of openness to trade. ${ }^{8}$ Note that all numbers reported in table 2 represent cumulative multipliers over the entire transition phase of $T$ periods: $\sum_{t=1}^{T}\left(\Delta y_{t} \Delta g_{t}^{-1}\right)$ and $\sum_{t=0}^{T}\left(\Delta c_{t} \Delta g_{t}^{-1}\right)$. The main observations are the following: Firstly, exchange rate flexibility clearly decreases the cumulative fiscal multiplier in the long run (compare cases (1) and (2) in table 2). By switching from the full monetary policy setting to the one without exchange rate targeting, the fiscal multiplier on output decreases by 0.21 to 0.32 units of domestic currency. By how much exactly depends on the degree of openness to trade. Likewise, the fiscal multiplier on private consumption decreases by 0.15 to 0.39 units. Secondly, also openness to trade substantially decreases the cumulative fiscal multiplier. A change from the home biased case to the open case decreases the multiplier on output by 0.12 to 0.23 units, and the multiplier on consumption by 0.12 to 0.36 units, depending on the monetary policy regime that is in place.

Table 3 presents a distinction of fiscal multipliers for a low versus a high degree of capital mobility. ${ }^{9}$ Note that instead of cumulative multipliers, table 3 reports fiscal multipliers which are attained immediately in the first period of a shock: $\Delta y_{1} \Delta g_{1}^{-1}$ and $\Delta c_{1} \Delta g_{1}^{-1}$. The results show that switching from high to low costs of holding foreign capital increases the fiscal multiplier on output by 0.18 . This holds for the case of flexible prices, as will be discussed in the following section. Under the full monetary policy regime, the effect of capital mobility with respect to the multiplier on output is diminished.

\section{Mechanism of a Government Expenditure Shock}

In this section, the dynamics that drive the fiscal multipliers presented in the previous section are to be discussed in detail. With regard to the research question, special emphasis is laid on the role of openness. Note in advance that the model is linearly approximated around the steady state, so no logs are taken. Whenever an impulse response function (IRF) is displayed in absolute terms, in contrast to a relative IRF or a multiplier, its values represent actual deviations from the steady state in levels. With respect to the components of aggregate demand, this makes comparisons of the IRFs more illustrative.

\subsection{Response of Demand}

Figure 1 presents the response of aggregate demand and its components to a fiscal shock. The shock to government spending has a size of one unit of domestic currency. The responses are denoted in absolute levels. Output reacts more strongly than government spending itself, hence there is a multiplier larger than one. Private

\footnotetext{
${ }^{8} \mathrm{~A}$ home bias is modeled by calibrating $\omega=0.85$, which is the same calibration as it is used by Dellas et al. (2005). To model the case where households have a high preference for foreign goods, the preference parameter is decreased to $\omega=0.01$.

${ }^{9}$ In the latter case, $\chi=0.01$, while in the case of low capital mobility $\chi=1000$. For table 3 , $\theta=0.5$ and $\gamma_{e}=1.5$ are assumed, which represents a slight change compared to the benchmark calibration.
} 
consumption responds less strongly to the fiscal shock, but also in a positive way. Monetary policy follows an interest rate rule with inflation targeting and output gap targeting. By consequence, the domestic interest rate increases in response to the fiscal shock, as shown in figure 2. In figure 3, the cumulative multiplier effects of the fiscal shock is shown. They are presented separately for aggregate output and private consumption. The cumulative multiplier on output lies above one, converging to 1.09 in the limit, while the cumulative multiplier on private consumption is also positive and converges to 0.15 .

\subsection{Components of the Fiscal Multiplier}

The fiscal multiplier is driven by four main components: (1) A negative wealth effect, which is typical for NK models, (2) a substitution effect that is due to counter-cyclical firm markups (the real wage increases and households substitute consumption for leisure), (3) a currency effect causing domestic and foreign demand to differ in their elasticity to the domestic price, and (4) an interest rate effect which is related to exchange rate targeting.

\subsubsection{Wealth Effect}

As it is typical for theoretical NK models, a positive government spending shock has a negative wealth effect on the households. The government raises the tax it collects from each household in order to finance its expenditure. It buys a share of total output of domestic firms. These goods are not redistributed to the households or other agents in the economy such that they could be used in any utility-delivering or productive way. (An alternative way of modeling is that households get direct utility from government expenditures, as it is done f.e. by Gali and Monacelli (2008).) Hence, households get poorer and therefore increase their work effort. Aggregate output increases in response.

\subsubsection{Substitution Effect (Counter-Cyclical Markups)}

The mechanism of deep habit formation is explained in technical detail in sections 2.1.2 and 2.3. In short, at the level of the individual good, $i$, it implies that having consumed $i$ in the past increases the marginal utility of future consumption of $i$ for a given household.

The monopolistically competitive firms take advantage and set the wage rate and the price of their goods such that their markups move in counter-cyclical fashion. There are two reasons for this kind of behavior of the firms. Firstly, they take into account the intra-temporal effect of an increase in aggregate demand, which raises the price elasticity of the demand each individual firm $i$ faces. Secondly, by lowering today's markup, the firms can acquire customers that will return in the future.

Figure 4 presents the responses of the firm markup, the real wage rate, and the price of domestic goods. These responses are denoted in relative terms, representing deviations from steady state in percentages. Evidently, movements in the markup take place mainly through changes in the real wage, while the price of domestic goods shows little movement. These results are entirely consistent with Ravn et al. (2008) who show that in response to a shock in government spending the markup of domestic 
firms decreases, a result which is mainly based on an increasing domestic wage rate (Ravn et al. 2008, figures 3 and 4). Cantore et al. (2012) find that in response to a government spending shock, the real wage increases and does so virtually as a mirror image of the decreasing firm markup (Cantore et al. 2012, figure 1). Note that it is the formation of 'deep' habits which causes these kind of dynamics; If the intensity of habit formation is turned down to zero, represented by the parameter $\theta$, then the model goes back to a more classic mechanism, where prices increase and wages decrease as a result of a fiscal expansion. Note also that the real wage converges back to its steady state rather rapidly; taking fewer periods to do so than the response of government spending.

One can ask the question whether it is true that real-world markups fall in response to a fiscal expansion. For example, Perotti (2008) provides evidence from several countries based on a structural VAR (including the United States and the United Kingdom) which is consistent with the real wage increasing in response to a fiscal policy expansion. In the present model, similarly to the model of Ravn et al. (2008), the markup equals the inverse of the domestic real product wage. Therefore, real product wages which have been reported to increase in response to a positive government spending shock by Perotti (2008) are consistent with counter-cyclical markups.

This substitution effect of counter-cyclical markups occurs in addition to the wealth effect described above. It means that households increase their work effort even further in response to a fiscal shock, substituting consumption for leisure. Simultaneously, the substitution effect compensates the negative wealth effect with respect to consumption, such that consumption increases in response to the fiscal shock (for most calibrations). This mechanism boosts the output multiplier.

\subsubsection{Currency Effect and Exchange Rate Flexibility}

Exchange rate flexibility increases the fiscal multiplier in the short run, but decreases it in the long run. Both the currency effect described in this paragraph and the interest rate effect described in the following are related to the role of exchange rate flexibility in this respect. The forward-looking households (with a discount factor of $\beta=0.99$ ) seek to smoothen out their consumption over time. Therefore, they spend part of their additional budget on bonds. The higher demand for foreign assets causes the domestic currency to depreciate in the short term. Figure 5 shows the resulting increase in the real exchange rate, as well as the response of net foreign bonds held by the domestic economy. ${ }^{10}$ Foreign consumers react to this currency depreciation by demanding more domestic goods, which consequently yields a positive trade balance of the domestic economy (see figure 6). Through this mechanism, the fiscal multiplier is amplified. Hence, a more reactive/flexible exchange rate increases the fiscal multiplier in the short term during the transition phase after the spending shock. Note that this is a short term effect. It diminishes as the households sell out their foreign bonds over time, and the real exchange rate and the trade balance converge back to steady state rather rapidly.

\footnotetext{
${ }^{10}$ The IRFs are denoted in absolute terms. Note that in steady state foreign bond holdings are zero, while the real exchange rate is equal to one.
} 


\subsubsection{Interest Rate Effect and Exchange Rate Flexibility}

Figure 7 presents the cumulative fiscal multiplier, both for the setting with exchange rate targeting and for the setting without exchange rate targeting. Under an exchange rate targeting rule, the domestic interest rate increases (further) in response to the fiscal expansion. This gives the forward looking households an incentive to shift even more consumption over time, meaning to consume less in the short term and more in the long term. This mechanism is intensified by a more rigid exchange rate targeting policy. Accordingly, if exchange rate targeting becomes more pronounced, the fiscal multiplier gets higher in the long run, and lower in the short run.

\subsection{Openness to Trade}

Openness to trade decreases the fiscal multiplier. Figures 8 and 9 illustrate how the fiscal multiplier on output and on consumption differs depending on whether the households have a home bias or whether they are fully open to trade. The effect of openness to trade on the fiscal multiplier is closely related to the mechanism of countercyclical markups. The domestic households decide how to spend the additional budget they have due to higher wages and a higher work effort. Their openness preference has an important effect on their decision. With respect to the fiscal multiplier, it is vital whether the households focus their additional demand on domestic goods, or whether they pass it on to foreign suppliers.

\subsection{Capital Mobility}

Capital mobility increases the fiscal multiplier (in the short run). Figure 10 reports the cumulative fiscal multiplier on output and on consumption in two separate graphs in the top row. Each of these two graphs shows the multiplier for a low and a high degree of capital mobility (represented by the parameter $\chi$ ). The other plots show impulse response functions in absolute levels. Prices are flexible in this setting. The three graphs in the middle row refer to the substitution effect (of counter-cyclical firm markups) which is described above, and the third row illustrates the currency effect. High costs of holding foreign bonds (a high $\chi$ ) make it expensive for domestic households to invest in foreign bonds. As a result, the otherwise larger increase in the net foreign asset position in response to a spending shock (as it is described above in terms of the currency effect) is diminished. Consequently, the domestic currency depreciates less strongly against the foreign currency. Finally, the increase in both the foreign demand for domestic goods and the trade balance is diminished, and hence the fiscal multiplier becomes smaller. In other words, restrictions on capital mobility reduce the otherwise larger positive effect of foreign demand on the multiplier of a domestic fiscal expansion. As shown by the three graphs in the second row of figure 10, firm markups and real wages do not respond significantly to changes in capital mobility.

As discussed above, the currency effect is short-term. Therefore, the decrease in the fiscal multiplier due to low capital mobility is also a short-term effect. Note that capital mobility only significantly influences the fiscal multiplier if monetary policy 
does not follow exchange rate targeting. This is due to the latter having the analogous effect of keeping the value of the domestic currency stable.

\section{Conclusion}

This paper analyzes the implications of openness to trade, capital mobility, and exchange rate flexibility for the fiscal multiplier. I propose a dynamic New Open Economy Macroeconomics model which yields a mechanism of the effect of economic openness as a determinant of the fiscal multiplier. A key element is given by counter-cyclical firm markups. The resulting substitution effect for households creates a positive response of consumption to a fiscal shock. Hereby, a negative effect of openness to trade on the fiscal multiplier is created, which is a main feature of the model.

The main implications are: Openness to trade limits the fiscal multiplier, while capital mobility increases the fiscal multiplier in the short run. In the limit, the effect of capital mobility is close to zero. Further, in the short run of the transition phase after a shock, flexible exchange rates can temporarily lead to a higher multiplier, an effect which diminishes over time. In the (long-run) equilibrium, exchange rate flexibility decreases the fiscal multiplier. In this sense, this dynamic analysis allows for a more detailed interpretation than a static model, such as the IS-LM model. Also, the model predicts a fundamentally different role of capital mobility compared to the IS-LM model. The implications are consistent with empirical evidence.

\section{Acknowledgements}

I thank Harris Dellas and Fabrice Collard from the Department of Economics of the University of Bern for their advice and support. I am also grateful to Simon Wieser from the Winterthur Institute of Health Economics for the encouragement to pursue a publication of this essay. Further, I thank my former colleagues Jürg Adamek, Guido Baldi, Philipp Wegmüller, and Marc Zahner for fruitful discussions related to this project. 


\section{A Appendix}

\section{A.1 FOC of the Households with Respect to Foreign Bonds}

Equation (6), the first-order condition of the representative domestic household with respect to foreign bonds, $B_{t}^{f}$, is derived according to:

$$
\begin{aligned}
0 \stackrel{!}{=} \frac{\partial \mathcal{L}}{\partial B_{t}^{f}} & =P_{t} e_{t}+\chi P_{t} e_{t}^{2} B_{t}^{f}-\beta \frac{\Lambda_{t+1}}{\Lambda_{t}} e_{t+1} R_{t}^{\star} P_{t} \\
1+\chi e_{t} B_{t}^{f} & =\beta \frac{\Lambda_{t+1}}{\Lambda_{t}} R_{t}^{\star} \frac{e_{t+1}}{e_{t}} \\
\underbrace{\Lambda_{t}}_{=\lambda_{t} / P_{t}}(1+\chi \overbrace{b_{t}^{f}}^{e_{t} B_{t}^{f}} & =\beta \underbrace{\Lambda_{t+1}}_{=\lambda_{t+1} / P_{t+1}} R_{t}^{\star} \frac{e_{t+1}}{e_{t}} \\
\lambda_{t} & =\beta \frac{R_{t}^{\star}}{1+\chi b_{t}^{f}} \cdot \frac{e_{t+1}}{e_{t}} \cdot \frac{\lambda_{t+1}}{\pi_{t+1}}
\end{aligned}
$$

\section{A.2 FOCs of the Domestic Firms}

Similarly to the model by Ravn et al. (2008), the Lagrangian of firm $i$ is given by

$$
\begin{aligned}
& \mathcal{L}=\mathbb{E}_{0} \sum_{t=0}^{\infty} \Phi_{0, t}\left\{\left[P_{t}^{d}(i)-W_{t}\right] \cdot\left[x_{c, t}^{d}(i)+x_{g, t}^{d}(i)+x_{c, t}^{d \star}(i)\right]-\frac{\varphi_{p}}{2}\left(\frac{P_{t}^{d}(i)}{P_{t-1}^{d}(i)}-1\right)^{2} P_{t} h_{t}\right. \\
&+P_{t} \nu_{c, t}(i)\left[\left(\frac{P_{t}^{d}(i)}{P_{t}}\right)^{-\eta} c_{t}^{d}+\theta s_{c, t-1}^{d}(i)-x_{c, t}^{d}(i)\right] \\
&+P_{t} \nu_{g, t}(i)\left[\left(\frac{P_{t}^{d}(i)}{P_{t}}\right)^{-\eta} g_{t}^{d}+\theta s_{g, t-1}^{d}(i)-x_{g, t}^{d}(i)\right] \\
& \\
&+P_{t} \nu_{c, t}^{\star}(i)\left[\left(\frac{P_{t}^{d}(i)}{e_{t} P_{t}^{\star}}\right)^{-\eta} c_{t}^{d \star}+\theta s_{c, t-1}^{d \star}(i)-x_{c, t}^{d \star}(i)\right] \\
&+P_{t} \varrho_{c, t}(i)\left[s_{c, t}^{d}(i)-\rho s_{c, t-1}^{d}(i)-(1-\rho) x_{c, t}^{d}(i)\right] \\
&+P_{t} \varrho_{g, t}(i)\left[s_{g, t}^{d}(i)-\rho s_{g, t-1}^{d}(i)-(1-\rho) x_{g, t}^{d}(i)\right] \\
&+\left.+P_{t} \varrho_{c, t}^{\star}(i)\left[s_{c, t}^{d \star}(i)-\rho s_{c, t-1}^{d \star}(i)-(1-\rho) x_{c, t}^{d \star}(i)\right]\right\}
\end{aligned}
$$

The FOCs are derived with respect to $P_{t}^{d}(i), x_{c, t}^{d}(i), x_{g, t}^{d}(i), x_{c, t}^{d \star}(i), s_{c, t}^{d}(i), s_{g, t}^{d}(i)$, and $s_{c, t}^{d \star}(i)$.

$$
\begin{aligned}
\frac{\partial \mathcal{L}}{\partial P_{t}^{d}(i)}= & y_{t}(i)-\varphi_{p}\left[\frac{P_{t}^{d}(i)}{P_{t-1}^{d}(i)}-1\right] \frac{P_{t}}{P_{t-1}^{d}(i)} h_{t} \\
& -\eta \frac{P_{t}}{P_{t}}\left[\frac{P_{t}}{P_{t}^{d}(i)}\right]^{1+\eta}\left[\nu_{c, t}(i) c_{t}^{d}+\nu_{g, t}(i) g_{t}^{d}\right]-\eta \frac{P_{t}}{e_{t} P_{t}^{\star}}\left[\frac{e_{t} P_{t}^{\star}}{P_{t}^{d}(i)}\right]^{1+\eta} \nu_{c, t}^{\star}(i) c_{t}^{d \star} \\
& +\Phi_{t, t+1} \mathbb{E}_{t}\left\{\varphi_{p} P_{t+1} \frac{P_{t+1}^{d}(i)}{\left[P_{t}^{d}(i)\right]^{2}}\left[\frac{P_{t+1}^{d}(i)}{P_{t}^{d}(i)}-1\right] h_{t+1}\right\} \stackrel{!}{=} 0
\end{aligned}
$$


where $\Phi_{t, t+1}=\beta \Lambda_{t+1} \Lambda_{t}^{-1}$, with $\Lambda_{t}$ being the Lagrange multiplier. The demand functions of the domestic household and the government yield the following conditions:

$$
\begin{aligned}
{\left[\frac{P_{t}}{P_{t}^{d}(i)}\right]^{1+\eta} c_{t}^{d} } & =\frac{P_{t}}{P_{t}^{d}(i)}\left[x_{c, t}^{d}(i)-\theta s_{c, t-1}^{d}(i)\right] \\
{\left[\frac{P_{t}}{P_{t}^{d}(i)}\right]^{1+\eta} g_{t}^{d} } & =\frac{P_{t}}{P_{t}^{d}(i)}\left[x_{g, t}^{d}(i)-\theta s_{g, t-1}^{d}(i)\right] \\
{\left[\frac{e_{t} P_{t}^{\star}}{P_{t}^{d}(i)}\right]^{1+\eta} c_{t}^{d \star} } & =\frac{e_{t} P_{t}^{\star}}{P_{t}^{d}(i)}\left[x_{c, t}^{d \star}(i)-\theta s_{c, t-1}^{d}(i)\right]
\end{aligned}
$$

Hence, the FOC with respect to $P_{t}^{d}(i)$ can be re-written as:

$$
\begin{array}{r}
y_{t}(i)-\varphi_{p}\left[\frac{P_{t}^{d}(i)}{P_{t-1}^{d}(i)}-1\right] \frac{P_{t}}{P_{t-1}^{d}(i)} h_{t} \\
-\eta \frac{P_{t}}{P_{t}^{d}(i)}\left\{\nu_{c, t}(i)\left[x_{c, t}^{d}(i)-\theta s_{c, t-1}^{d}(i)\right]\right. \\
\left.+\nu_{g, t}(i)\left[x_{g, t}^{d}(i)-\theta s_{g, t-1}^{d}(i)\right]+\nu_{c, t}^{\star}(i)\left[x_{c, t}^{d \star}(i)-\theta s_{c, t-1}^{d \star}(i)\right]\right\} \\
+\beta \varphi_{p} \frac{\Lambda_{t+1}}{\Lambda_{t}} \mathbb{E}_{t}\left\{P_{t+1} \frac{P_{t+1}^{d}(i)}{\left[P_{t}^{d}(i)\right]^{2}}\left[\frac{P_{t+1}^{d}(i)}{P_{t}^{d}(i)}-1\right] h_{t+1}\right\} \stackrel{!}{=} 0
\end{array}
$$

Further FOCs are given by

$$
\begin{array}{lllll}
\frac{\partial \mathcal{L}}{\partial x_{c, t}^{d}(i)}=P_{t}^{d}(i)-W_{t}-P_{t} \nu_{c, t}(i)-(1-\rho) P_{t} \varrho_{c, t}(i) \stackrel{!}{=} & 0 & \\
\frac{\partial \mathcal{L}}{\partial x_{g, t}^{d}(i)}=P_{t}^{d}(i)-W_{t}-P_{t} \nu_{g, t}(i)-(1-\rho) P_{t} \varrho_{g, t}(i) \stackrel{!}{=} & 0 & \\
\frac{\partial \mathcal{L}}{\partial x_{c, t}^{d \star}(i)}=P_{t}^{d}(i)-W_{t}-P_{t} \nu_{c, t}^{\star}(i)-(1-\rho) P_{t} \varrho_{c, t}^{\star}(i) \stackrel{!}{=} & 0 & \\
\frac{\partial \mathcal{L}}{\partial s_{c, t}^{d}(i)}=P_{t} \varrho_{c, t}(i)+\beta \frac{\Lambda_{t+1}}{\Lambda_{t}}\left[P_{t+1} \nu_{c, t+1}(i) \theta-P_{t+1} \varrho_{t+1}(i) \rho\right] \stackrel{!}{=} & 0 \\
\frac{\partial \mathcal{L}}{\partial s_{g, t}^{d}(i)}=P_{t} \varrho_{g, t}(i)+\beta \frac{\Lambda_{t+1}}{\Lambda_{t}}\left[P_{t+1} \nu_{g, t+1}(i) \theta-P_{t+1} \varrho_{t+1}(i) \rho\right] \stackrel{!}{=} & 0 \\
\frac{\partial \mathcal{L}}{\partial s_{c, t}^{d \star}(i)}=P_{t} \varrho_{c, t}^{\star}(i)+\beta \frac{\Lambda_{t+1}}{\Lambda_{t}}\left[P_{t+1} \nu_{c, t+1}^{\star}(i) \theta-P_{t+1} \varrho_{t+1}^{\star}(i) \rho\right] \stackrel{!}{=} & 0
\end{array}
$$

Assuming that for a given type of good (domestic vs. foreign), a given type of consumer (private vs. public), and a given location of a consumer (domestic vs. foreign), initial habit stocks are identical across varieties $i$. Then, in a symmetric equilibrium, it must hold that $P_{t}^{d}(i)=P_{t}^{d}$ and therefore $x_{c, t}^{d}(i)=x_{c, t}^{d}, x_{g, t}^{d}(i)=x_{g, t}^{d}, x_{c, t}^{d \star}(i)=x_{c, t}^{d \star}, s_{c, t}^{d}(i)=$ $s_{c, t}^{d}, s_{g, t}^{d}(i)=s_{g, t}^{d}$, and $s_{c, t}^{d \star}(i)=s_{c, t}^{d \star}$. That is, all the $i$ s drop. Therefore, the first-order 
conditions of the general equilibrium are equal to

$$
\begin{aligned}
0= & p_{t}^{d} y_{t}-\varphi_{p}\left(\pi_{t}^{d}-1\right) \pi_{t}^{d} h_{t}-\eta\left[\nu_{c, t}\left(x_{c, t}^{d}-\theta s_{c, t-1}^{d}\right)\right. \\
& \left.+\nu_{g, t}\left(x_{g, t}^{d}-\theta s_{g, t-1}^{d}\right)+\nu_{c, t}^{\star}\left(x_{c, t}^{d \star}-\theta s_{c, t-1}^{d \star}\right)\right] \\
& +\beta \varphi_{p} \frac{\lambda_{t+1}}{\lambda_{t}} \pi_{t+1}^{d}\left(\pi_{t+1}^{d}-1\right) h_{t+1} \\
p_{t}^{d}-w_{t} \frac{P_{t}^{d}}{P_{t}^{d}}= & \nu_{c, t}+(1-\rho) \varrho_{c, t} \\
p_{t}^{d}-w_{t} \frac{P_{t}^{d}}{P_{t}^{d}}= & \nu_{g, t}+(1-\rho) \varrho_{g, t} \\
p_{t}^{d}-w_{t} \frac{P_{t}^{d}}{P_{t}^{d}=} & \nu_{c, t}^{\star}+(1-\rho) \varrho_{c, t}^{\star} \\
\varrho_{c, t}= & \beta \frac{\lambda_{t+1}}{\lambda_{t}}\left(\rho \varrho_{c, t+1}-\theta \nu_{c, t+1}\right) \\
\varrho_{g, t}= & \beta \frac{\lambda_{t+1}}{\lambda_{t}}\left(\rho \varrho_{g, t+1}-\theta \nu_{g, t+1}\right) \\
\varrho_{c, t}^{\star}= & \beta \frac{\lambda_{t+1}}{\lambda_{t}}\left(\rho \varrho_{c, t+1}^{\star}-\theta \nu_{c, t+1}^{\star}\right)
\end{aligned}
$$

where $\pi_{t}^{d}=P_{t}^{d}(i)\left[P_{t-1}^{d}(i)\right]^{-1}, \lambda_{t+1} \lambda_{t}^{-1}=\Lambda_{t+1} P_{t+1} \Lambda_{t}^{-1} P_{t}^{-1}$, and $W_{t}=w_{t} P_{t}$. I define $p_{t}^{d}=P_{t}^{d} P_{t}^{-1}$ and $p_{t}^{f}=P_{t}^{f}\left(P_{t}^{\star}\right)^{-1}$, where $P_{t}^{\star}$ is the foreign CPI which is exogenous to the domestic small open economy. In combination with the definition of the domestic real exchange rate, $\operatorname{rer}_{t}=e_{t} P_{t}^{\star} P_{t}^{-1}$, this yields $\operatorname{rer}_{t} p_{t}^{f}=e_{t} P_{t}^{f} P_{t}^{-1}$. The last equality allows for simplification of the above mentioned budget constraints of the producer's problem. In a symmetric equilibrium, where there is no difference between any of the agents $i$, it must hold that:

$$
\begin{aligned}
x_{c, t}^{d} & =\left(p_{t}^{d}\right)^{-\eta} c_{t}^{d}+\theta s_{c, t-1}^{d} \\
x_{c, t}^{f} & =\left(\operatorname{rer}_{t} p_{t}^{f}\right)^{-\eta} c_{t}^{f}+\theta s_{c, t-1}^{f} \\
x_{g, t}^{d} & =\left(p_{t}^{d}\right)^{-\eta} g_{t}^{d}+\theta s_{g, t-1}^{d} \\
x_{c, t}^{d \star} & =\left(\frac{p_{t}^{d}}{r e r_{t}}\right)^{-\eta} c_{t}^{d \star}+\theta s_{c, t-1}^{d \star} \\
s_{c, t}^{d} & =\rho s_{c, t-1}^{d}+(1-\rho) x_{c, t}^{d} \\
s_{c, t}^{f} & =\rho s_{c, t-1}^{f}+(1-\rho) x_{c, t}^{f} \\
s_{g, t}^{d} & =\rho s_{g, t-1}^{d}+(1-\rho) x_{g, t}^{d} \\
s_{c, t}^{d \star} & =\rho s_{c, t-1}^{d \star}+(1-\rho) x_{c, t}^{d \star}
\end{aligned}
$$




\section{A.3 List of Conditions of the General Equilibrium}

$$
\begin{aligned}
& c_{t}^{\mathrm{obj}}=\left[\omega\left(c_{t}^{d}\right)^{1-1 / \xi}+(1-\omega)\left(c_{t}^{f}\right)^{1-1 / \xi}\right]^{\frac{1}{1-1 / \xi}} \\
& \lambda_{t} p_{t}^{d}=\left(c_{t}^{\mathrm{obj}}\right)^{\frac{1}{\xi}-\sigma} \omega\left(c_{t}^{d}\right)^{-\frac{1}{\xi}} \\
& \lambda_{t} \operatorname{rer}_{t} p_{t}^{f}=\left(c_{t}^{\mathrm{obj}}\right)^{\frac{1}{\xi}-\sigma}(1-\omega)\left(c_{t}^{f}\right)^{-\frac{1}{\xi}} \\
& \lambda_{t} w_{t}=\psi h_{t}^{\phi} \\
& \pi_{t+1}=\beta R_{t} \frac{\lambda_{t+1}}{\lambda_{t}} \\
& \pi_{t+1}=\beta \frac{R_{t}^{\star}}{1+\chi b_{t}^{f}} \cdot \frac{e_{t+1}}{e_{t}} \cdot \frac{\lambda_{t+1}}{\lambda_{t}} \\
& x_{c, t}^{d}=\left(p_{t}^{d}\right)^{-\eta} c_{t}^{d}+\theta s_{c, t-1}^{d} \\
& x_{c, t}^{f}=\left(\operatorname{rer}_{t} p_{t}^{f}\right)^{-\eta} c_{t}^{f}+\theta s_{c, t-1}^{f} \\
& x_{g, t}^{d}=\left(p_{t}^{d}\right)^{-\eta} g_{t}^{d}+\theta s_{g, t-1}^{d} \\
& x_{c, t}^{d \star}=\left(\frac{p_{t}^{d}}{r e r_{t}}\right)^{-\eta} c_{t}^{d \star}+\theta s_{c, t-1}^{d \star} \\
& s_{c, t}^{d}=\rho s_{c, t-1}^{d}+(1-\rho) x_{c, t}^{d} \\
& s_{c, t}^{f}=\rho s_{c, t-1}^{f}+(1-\rho) x_{c, t}^{f} \\
& s_{g, t}^{d}=\rho s_{g, t-1}^{d}+(1-\rho) x_{g, t}^{d} \\
& s_{c, t}^{d \star}=\rho s_{c, t-1}^{d \star}+(1-\rho) x_{c, t}^{d \star} \\
& 0=p_{t}^{d} y_{t}-\varphi_{p}\left(\pi_{t}^{d}-1\right) \pi_{t}^{d} h_{t}-\eta\left[\nu_{t}\left(x_{c, t}^{d}-\theta s_{c, t-1}^{d}+x_{g, t}^{d}-\theta s_{g, t-1}^{d}\right)\right. \\
& \left.+\nu_{t}^{\star}\left(x_{c, t}^{d \star}-\theta s_{c, t-1}^{d \star}\right)\right] \\
& +\beta \varphi_{p} \frac{\lambda_{t+1}}{\lambda_{t}} \pi_{t+1}^{d}\left(\pi_{t+1}^{d}-1\right) h_{t+1} \\
& w_{t}=p_{t}^{d}-\nu_{t}-(1-\rho) \varrho_{t} \\
& w_{t}=p_{t}^{d}-\nu_{t}^{\star}-(1-\rho) \varrho_{t}^{\star} \\
& \varrho_{t}=\beta \frac{\lambda_{t+1}}{\lambda_{t}}\left(\rho \varrho_{t+1}-\theta \nu_{t+1}\right) \\
& \varrho_{t}^{\star}=\beta \frac{\lambda_{t+1}}{\lambda_{t}}\left(\rho \varrho_{t+1}^{\star}-\theta \nu_{t+1}^{\star}\right) \\
& 1=\gamma p_{t}^{d}+(1-\gamma) \operatorname{rer}_{t} p_{t}^{f} \\
& c_{t}=x_{c, t}^{d}+x_{c, t}^{f} \\
& g_{t}=x_{g, t}^{d} \\
& y_{t}=x_{c, t}^{d}+x_{g, t}^{d}+x_{c, t}^{d \star} \\
& h_{t}=y_{t}+\frac{\chi}{2}\left(b_{t}^{f}\right)^{2}+\frac{\varphi_{p}}{2}\left(\pi^{d}-1\right)^{2} h_{t} \\
& b_{t}^{f}=\frac{e_{t}}{e_{t-1} \pi_{t}} R_{t-1}^{\star} b_{t-1}^{f}-h_{t}+y_{t}+x_{c, t}^{d \star}-x_{c, t}^{f} \\
& p_{t}^{d}=\frac{\pi_{t}^{d}}{\pi_{t}} p_{t-1}^{d}
\end{aligned}
$$




$$
\begin{aligned}
\operatorname{rer}_{t}= & \frac{p_{t}^{f}}{p_{t-1}^{f}} \cdot \frac{r e r_{t-1}}{\pi_{t}} \\
\left(c_{t}^{d \star}\right)^{-\sigma}= & \beta R_{t}^{\star}\left(c_{t+1}^{d \star}\right)^{-\sigma} \frac{p_{t}^{f}}{p_{t+1}^{f}} \\
\log \left(R_{t}\right)= & \rho_{r} \log \left(R_{t-1}\right)+ \\
& \left(1-\rho_{r}\right)\left\{\log (\bar{R})+\gamma_{\pi}\left[\log \left(\pi_{t}\right)-\log (\bar{\pi})\right]\right. \\
& \left.+\gamma_{y}\left[\log \left(y_{t}\right)-\log (\bar{y})\right]+\gamma_{e}\left[\log \left(e_{t}\right)-\log (\bar{e})\right]\right\} \\
\mu_{t}= & p_{t}^{d}-w_{t} \\
T B_{t}= & x_{c, t}^{d \star}-x_{c, t}^{f}
\end{aligned}
$$

where $\pi_{t}^{d}=P_{t}^{d}\left(P_{t-1}^{d}\right)^{-1}, W_{t}=w_{t} P_{t}, p_{t}^{d}=P_{t}^{d} P_{t}^{-1}, p_{t}^{f}=P_{t}^{f}\left(P_{t}^{\star}\right)^{-1}, p_{t}^{d \star}=P_{t}^{d \star} P_{t}^{-1}$, rer $_{t}$ $=e_{t} P_{t}^{\star} P_{t}^{-1}, \operatorname{rer}_{t} p_{t}^{f}=e_{t} P_{t}^{f} P_{t}^{-1}$, and $b_{t}^{f}=e_{t} B_{t}^{f}$. Note that $\theta^{c}=\theta^{g}=\theta^{\star}=\theta$ implies that in equilibrium $\nu_{c}=\nu_{g}=\nu$ and $\varrho_{c}=\varrho_{g}=\varrho$. The exogenous processes are given by

$$
\begin{aligned}
g_{t+1} & =\gamma^{g} g_{t}+\left(1-\gamma^{g}\right) \bar{g}+\varepsilon_{t+1}^{g} \\
c_{t+1}^{d \star} & =\gamma^{d \star} c_{t}^{d \star}+\left(1-\gamma^{d \star}\right) \bar{c}^{d \star}+\varepsilon_{t+1}^{d \star} \\
p_{t+1}^{f} & =\gamma^{f} p_{t}^{f}+\left(1-\gamma^{f}\right) \bar{p}^{f}+\varepsilon_{t+1}^{f}
\end{aligned}
$$

\section{References}

Auerbach, A. \& Gorodnichenko, Y. (2011). Measuring the Output Responses to Fiscal Policy. Manuscript submitted for publication.

Cantore, C., Levine, P., Melina, G., \& Pearlman, J. (2012). Fiscal Stimuli and Consolidations. Paper presented at the the European Monetary Forum Conference organized by Bank of Greece and the European Monetary Forum, Athens, 30-31 March, 2012.

Canzoneri, M. B., Collard, F., Dellas, H., \& Diba, B. (2009). Withering Government Spending Multipliers. Manuscript submitted for publication.

Canzoneri, M. B., Collard, F., Dellas, H., \& Diba, B. (2011). Fiscal Multipliers in Recessions. Manuscript submitted for publication.

Chintagunta, P., Kyriazidou, E., \& Perktold, J. (2001). Panel data analysis of household brand choices. Journal of Econometrics, July, 103(1-2), 111-153.

Colciago, A. (2006). Rule of thumb consumers, equilibrium determinacy and the effect of government spending shocks. Unpublished manuscript.

Collard, F., Dellas, H., \& Diba, B. (2011). Suite of Models for Dynare (Version 1.0). Unpublished manuscript.

Dellas, H., Neusser, K., \& Wälti, M. (2005). Fiscal Policy in Open Economies. Unpublished manuscript. 
Dixit, A. \& Stiglitz, J. (1977). Monopolistic Competition and Optimum Product Diversity. American Economic Review, 67(3), 297-308.

Fleming, M. (1962). Domestic Financial Policies under Fixed and Floating Exchange Rates. IMF Staff Paper Series, 9, 369-379.

Gali, J., Lopez-Salido, D., \& Valles, J. (2004). Rule-of-Thumb Consumers and the Design of Interest Rate Rules. Journal of Money, Credit and Banking, 36(4), 739-764.

Gali, J., Lopez-Salido, D., \& Valles, J. (2007). Understanding the Effects of Government Spending on Consumption. Journal of the European Economic Association, $5(1), 227-270$.

Gali, J. \& Monacelli, T. (2008). Optimal Monetary and Fiscal Policy in a Currency Union. Journal of International Economics, September, 76(1), 116-132.

Hall, R. E. (2009). By how much does GDP rise if the government buys more output? Unpublished manuscript.

Henderson, D. W. \& McKibbin, W. (1993). A Comparison of Some Basic Monetary Policy Regimes for Open Economies: Implications of Different Degrees of Instrument Adjustment and Wage Persistence. Carnegie-Rochester Conference Series on Public Policy, 39, 221-318.

Ilzetzki, E., Mendoza, E. G. \& Vegh, C. A. (2010). How Big (Small?) are Fiscal Multipliers? NBER Working Paper Series, Number 16479.

Kühn, S., Muysken, J., \& van Veen, T. (2008). The Adverse Effects of Government Spending in New Keynesian Models. Unpublished manuscript.

Mundell, R. (1962). Capital Mobility and Stabilization Policy under Fixed and Flexible Exchange Rates. Canadian Journal of Economic and Political Science, 29, 475-485.

Natvik, G. J. (2010). Government spending shocks and rule-of-thumb consumers: The role of steady state inequality. Manuscript submitted for publication.

Perotti, R. (2008). In search of the transmission mechanism for fiscal policy. NBER Macroeconomics Annual, 22, 169-226.

Ramey, V. A. (2011). Can governments purchases stimulate the economy? Journal of Economic Literature, 49(3), 673-685.

Ravn, M. O., Schmitt-Grohe, S., \& Uribe, M. (2005). Deep Habits. Review of Economic Studies, 73(1), 195-218.

Ravn, M. O., Schmitt-Grohe, S., \& Uribe, M. (2008). Explaining the Effects of Government Spending Shocks on Consumption and the Real Exchange Rate. NBER Working Paper Series, Number 13328.

Taylor, J. B. (1993). Discretion versus Policy Rules in Practice. Carnegie-Rochester Conference Series on Public Policy, 39, 195-214. 


\section{Tables}

Table 1: Benchmark Parameter Values

\begin{tabular}{l|lr}
\hline \hline Openness preference & $\omega$ & 0.850 \\
Habit persistence & $\rho$ & 0.900 \\
Habit formation & $\theta$ & 0.540 \\
Substitutability between varieties $i$ & $\eta$ & 5.000 \\
International substitutability $(d$ vs. $f)$ & $\xi$ & 1.500 \\
Discount factor & $\beta$ & 0.990 \\
Utility & $\sigma$ & 1.010 \\
Frisch elasticity & $(1+\phi)$ & 1.010 \\
Preference & $\psi$ & 2.144 \\
Price adjustment & $\varphi_{p}$ & 1.000 \\
Capital adjustment & $\chi$ & 10.000 \\
Persistence (policy rule) & $\rho_{R}$ & 0.010 \\
Inflation coefficient (policy rule) & $\gamma_{\pi}$ & 0.500 \\
Output gap coefficient (policy rule) & $\gamma_{y}$ & 0.050 \\
Exchange rate coefficient (policy rule) & $\gamma_{e}$ & 1.000 \\
\hline \hline
\end{tabular}

Table 2: Cumulative Fiscal Multiplier in the Limit

Aggregate Output Private Consumption

\begin{tabular}{lcc}
\hline \hline & (1) Full Monetary Policy (Benchmark) \\
\hline Home Bias $(\omega=0.85)$ & 1.30 & 0.30 \\
Open for Trade $(\omega=0.01)$ & 1.18 & 0.18 \\
& & \\
\hline \hline \multicolumn{2}{l}{ (2) } & Flexible Exchange Rate \\
\hline Opome Bias $(\omega=0.85)$ & 1.09 & 0.15 \\
Open for Trade $(\omega=0.01)$ & 0.86 & -0.21 \\
\hline \hline
\end{tabular}


Table 3: Immediate Fiscal Multiplier (First Period)

\begin{tabular}{lcc}
\hline \hline & Aggregate Output & Private Consumption \\
\hline \hline & (1) Full Monetary Policy $\left(\right.$ Benchmark $\left.^{*}\right)$ \\
\hline Immobile Capital $(\chi=1000)$ & 1.30 & 0.30 \\
Mobile Capital $(\chi=0.01)$ & 1.29 & 0.22 \\
\hline \hline & & \\
\hline Immobile Capital $(\chi=1000)$ & $(3)$ Flexible Prices & 0.34 \\
Mobile Capital $(\chi=0.01)$ & 1.34 & 0.35 \\
& & \\
\hline \hline
\end{tabular}




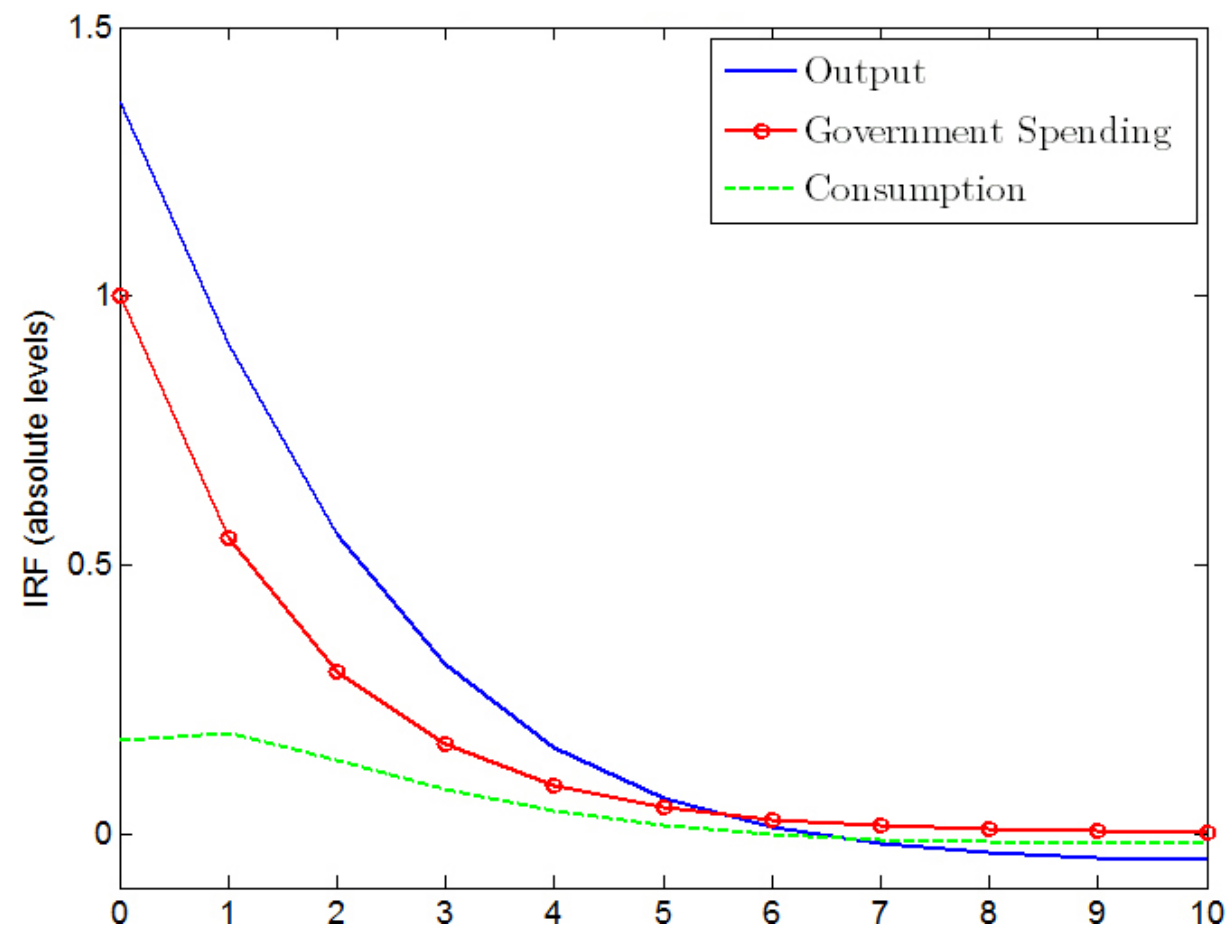

Figure 1: Impulse Responses (in Levels) to a Government Spending Shock

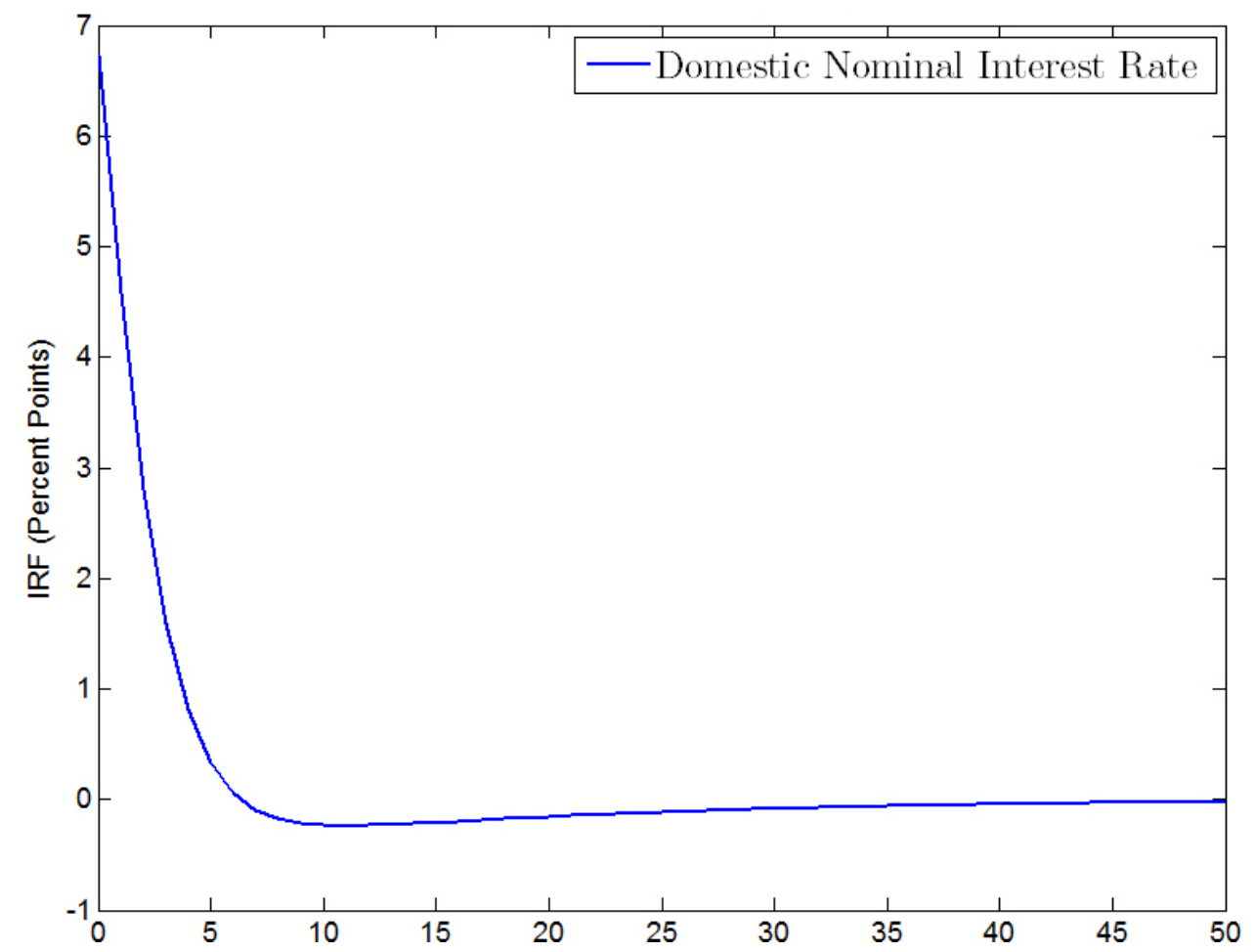

Figure 2: Relative Impulse Responses (in Percentage Points of the Steady State) 


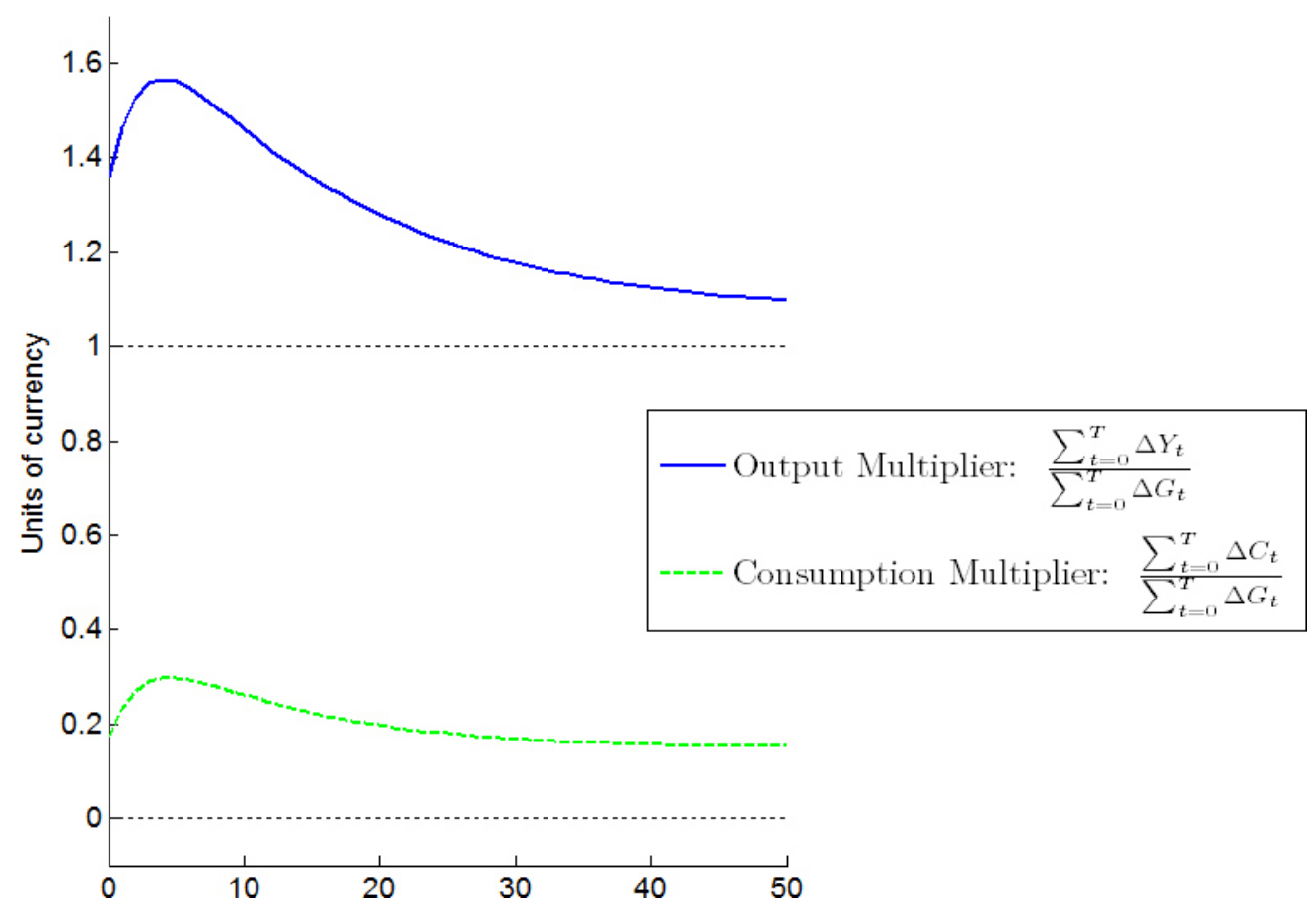

Figure 3: Cumulative Multipliers of a Government Spending Shock

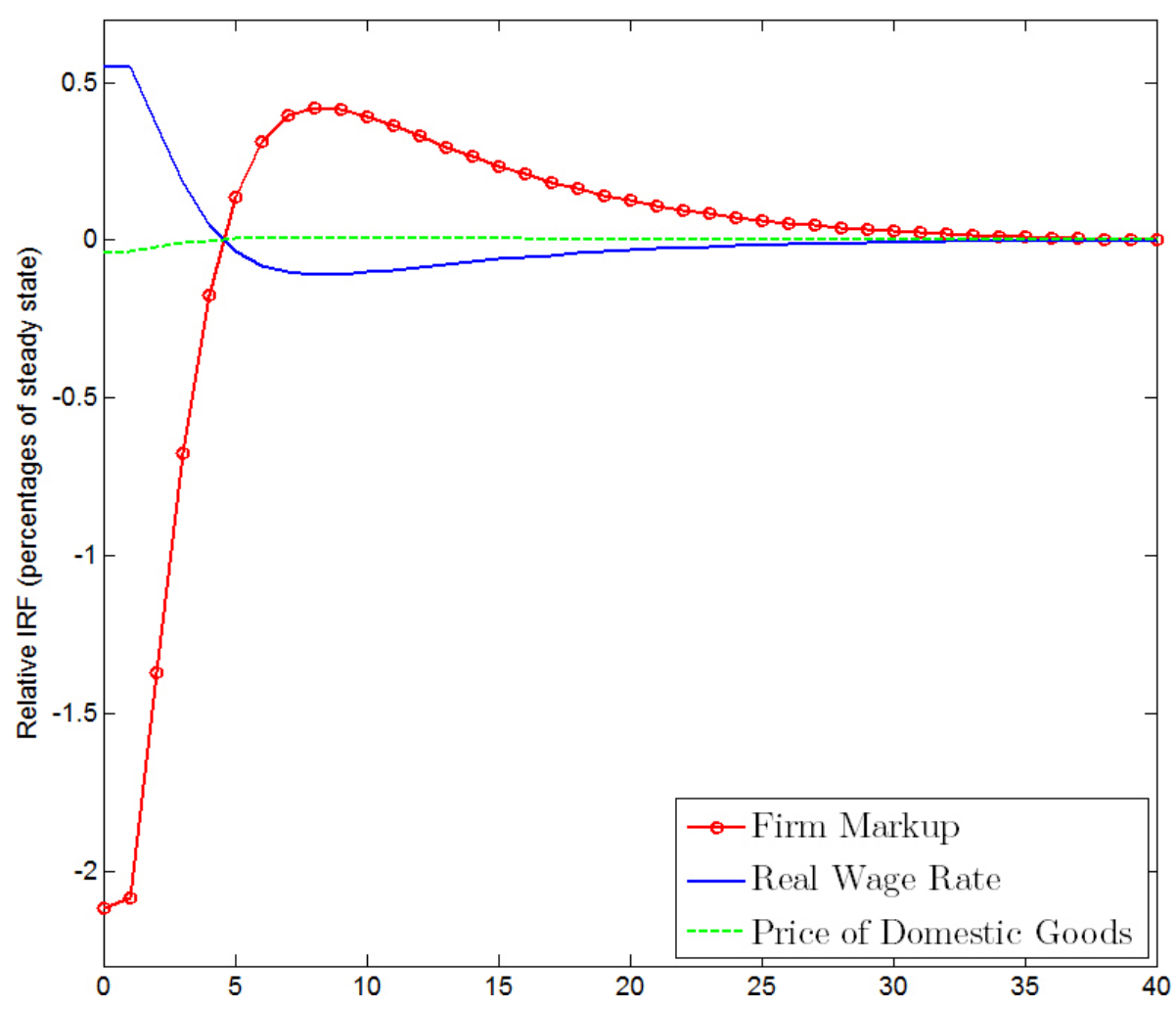

Figure 4: Relative Impulse Responses (in Percentages of the Steady State) 


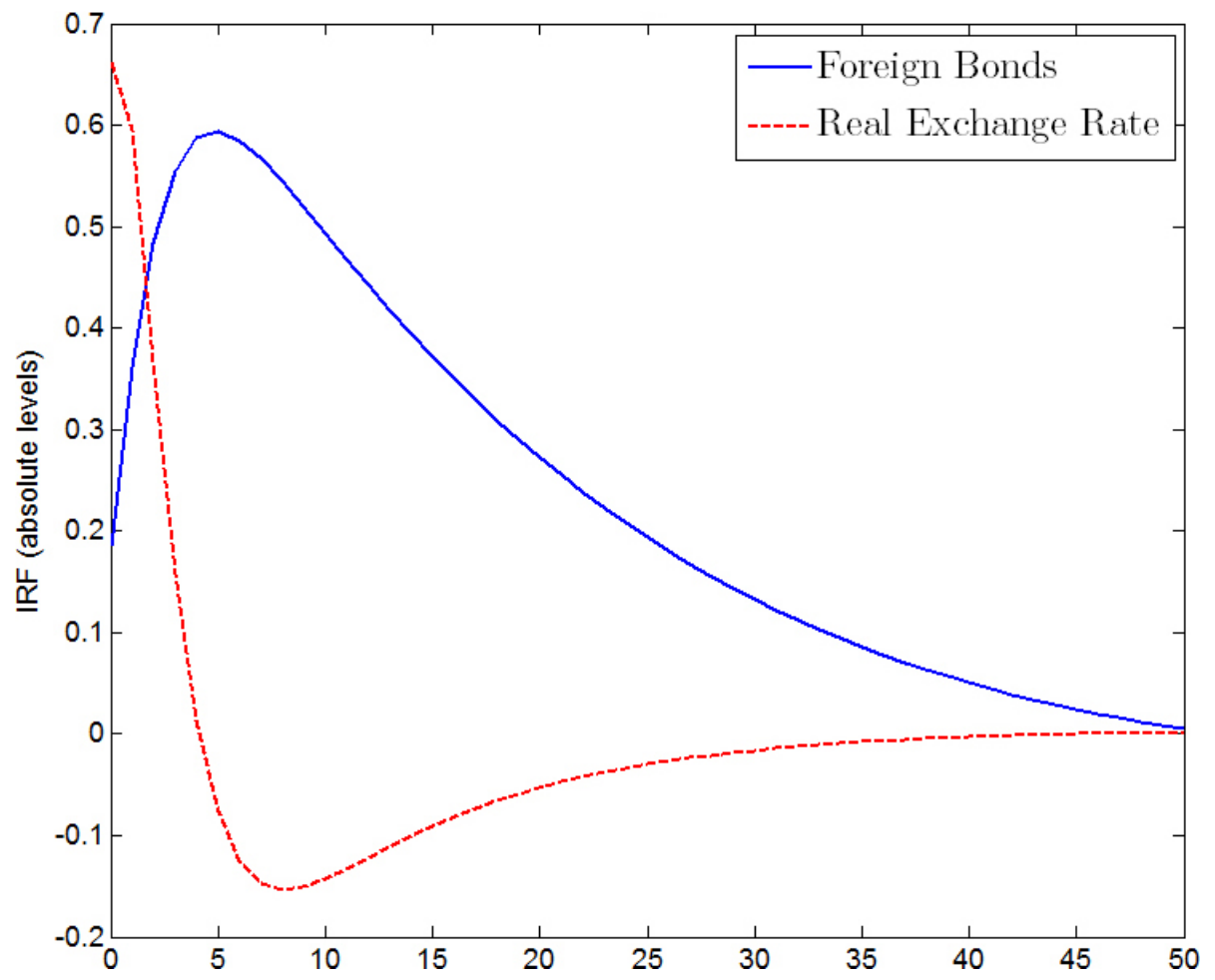

Figure 5: Impulse Responses (in Levels) to a Government Spending Shock

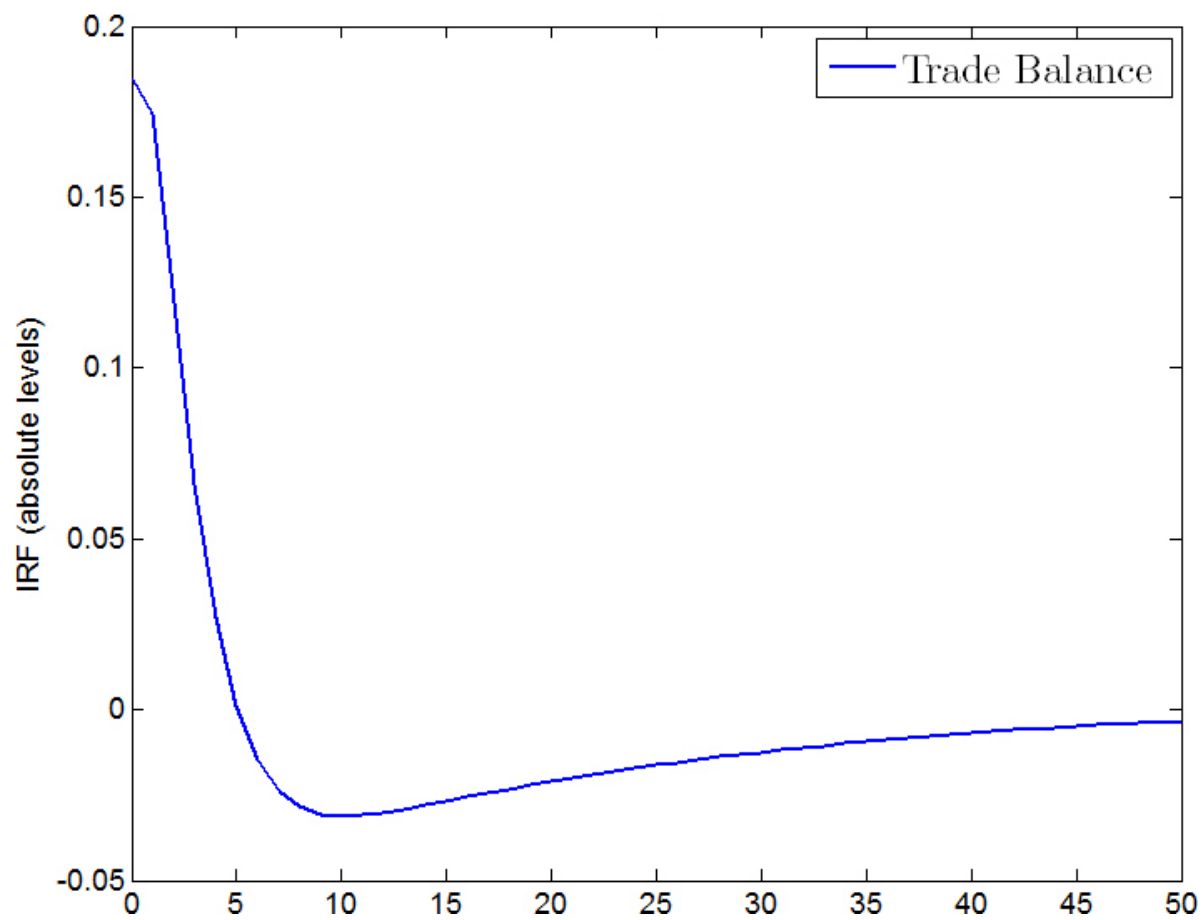

Figure 6: Impulse Responses (in Levels) to a Government Spending Shock 


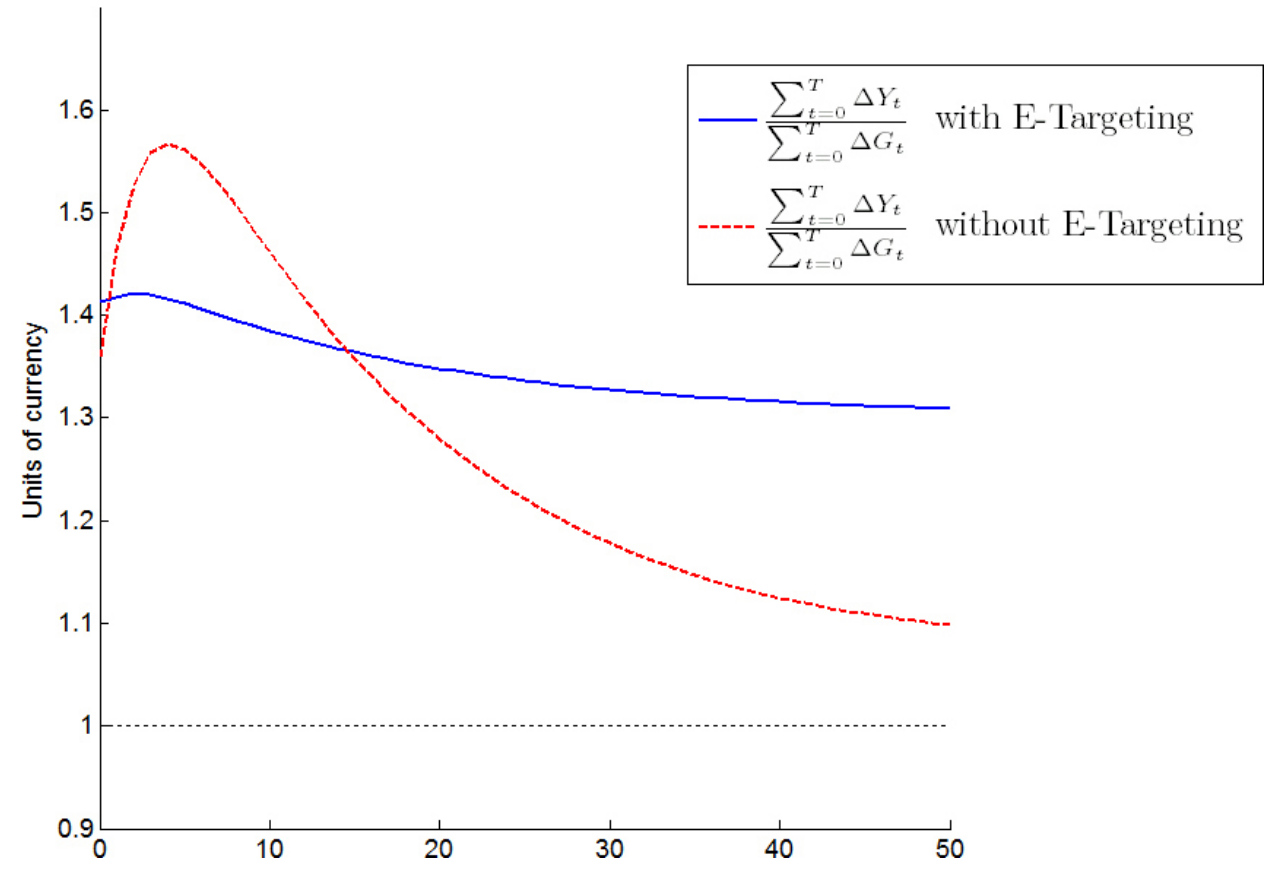

Figure 7: Cumulative Output Multipliers of a Government Spending Shock for Different Monetary Policy Regimes

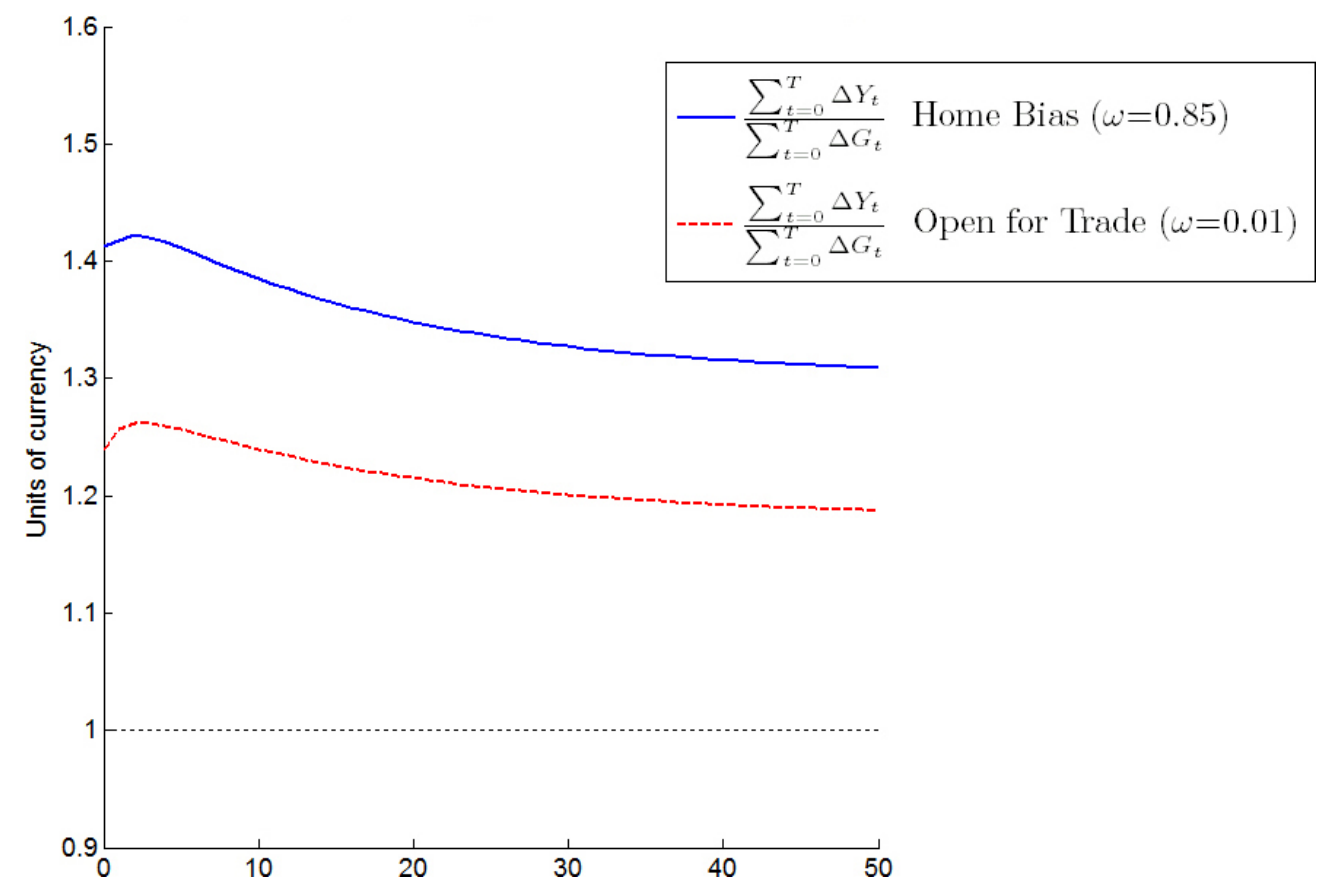

Figure 8: Cumulative Output Multipliers of a Government Spending Shock for Different Degrees of Openness to Trade 


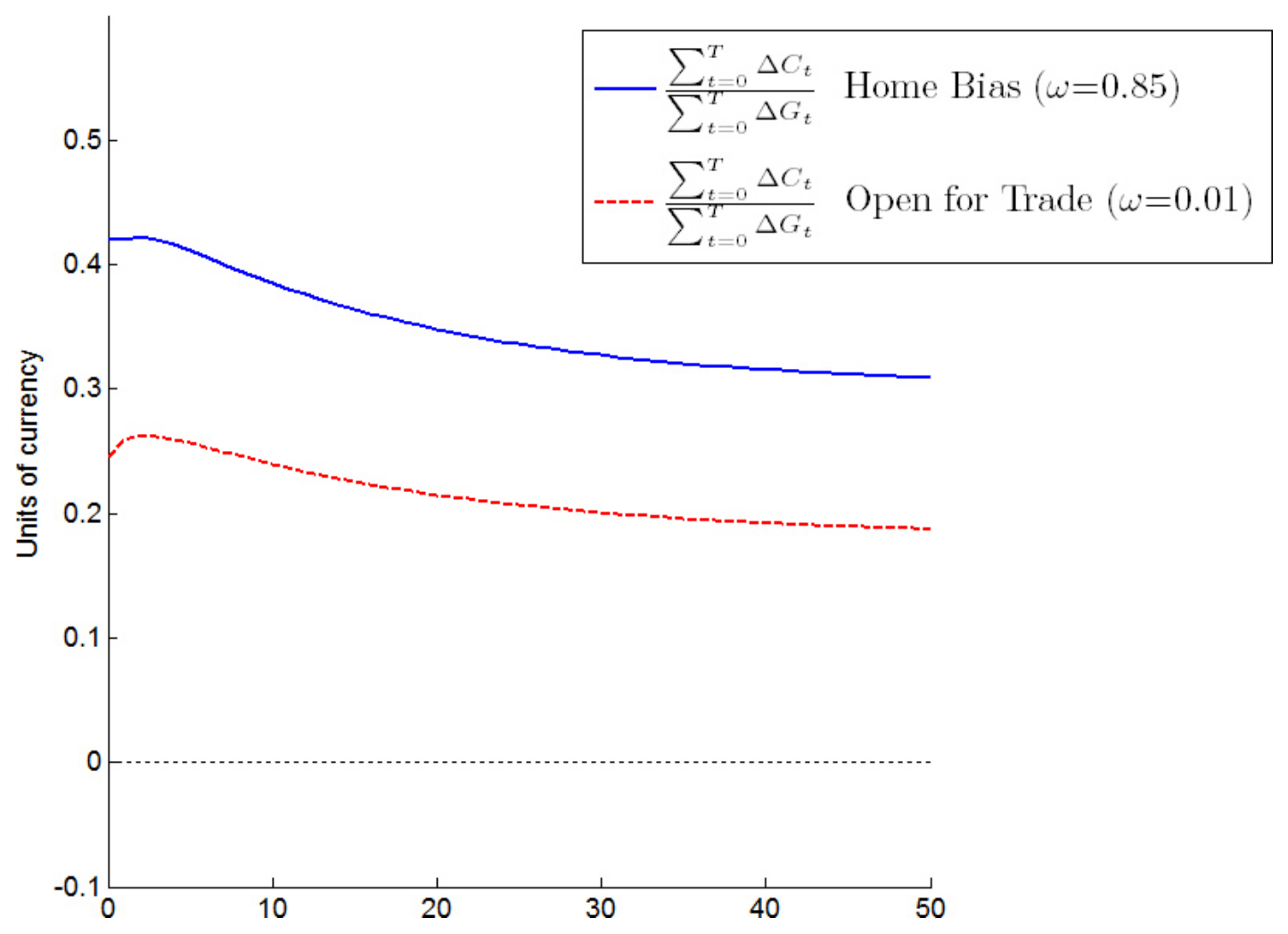

Figure 9: Cumulative Consumption Multipliers of a Government Spending Shock for Different Degrees of Openness to Trade 

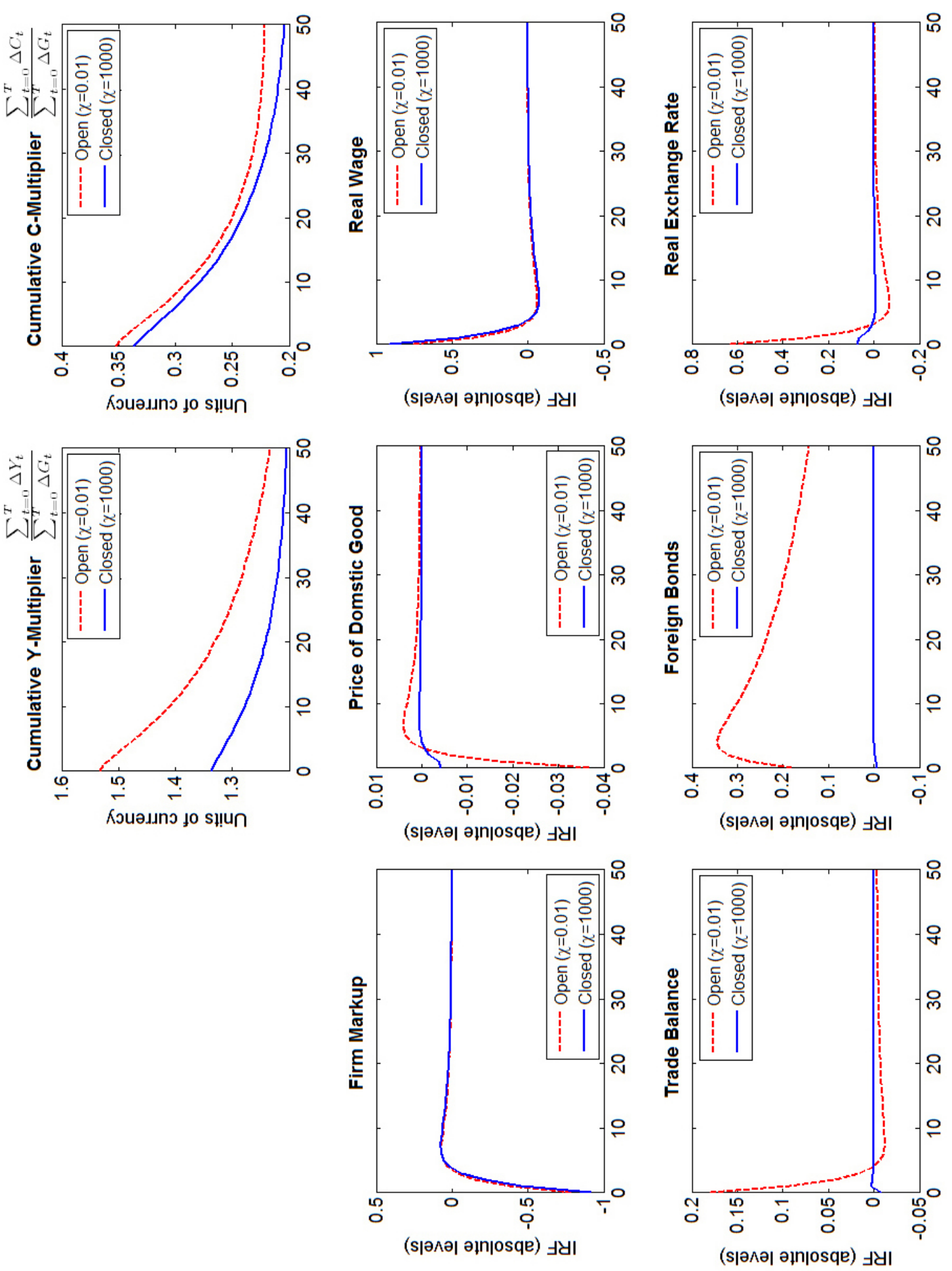

Figure 10: Responses to a Government Spending Shock for Different Degrees of Capital Mobility 